\title{
Do Words Really Never Harm Us? An Exploration of the Relationship between Stereotypes, Linguistic Bias and Gender Inequalities in the Irish Naval Service
}

\section{Elaine Moloney}

The Irish Defence Forces is committed to increasing female participation to 12 per cent by 2023. However, numbers have never surpassed 8 per cent. This article aims to shine a light on a possible explanation or contributing factor of this by exploring the relationship between stereotypes, linguistic bias, and gender inequalities in the Irish Naval Service (NS). Building on Beukeboom and Burgers' Social Categories and Stereotypes Communications (SCSC) framework, this study asks if gender stereotypes and gender biased language exist in the NS and, if so, how prevalent are they and what are their consequences on gender inequality in the organisation.

This study highlights a reliance on gender roles within the NS which ascribe men a higher status than women and which view women as mothers. Consequently, women appear to be unfairly disadvantaged when it comes to career progression and advancement. The study also suggests that men are inclined to portray themselves in a more favourable light while also highlighting the negative behaviours of women. These findings support the notion that gender stereotypes and gender biased language are active in the NS and suggest a relationship between their use and gender inequalities in the NS. On this basis, it is recommended that NS adopts an integrated and continuous training programme that raises greater awareness of stereotypes, linguistic biases, and the negative consequences of their use. Further research is needed to identify further areas that stereotypes, and linguistic biases could be contributing to gender inequalities in the NS.

Since the twentieth century, gender equality has become a prominent and permanent fixture on the global agenda, with organisations such as the United Nations (UN) and the European Union (EU) actively committed to eradicating the existence of gender inequalities. Both the UN and EU have introduced numerous international treaties, resolutions and directives promoting gender equality and the empowerment of women that Ireland, the European, and Global community has committed to adhering to. The most notable of these are the UN Convention of the elimination of all forms of discrimination against women (CEDAW), UN Security Council Resolution (UNSCR) 1325 on women, peace and security, UN Sustainable Development Goals (SDG), and EU directive 2002/73/EC. However, even with these global commitments, sobering 
evidence, such as the Equal Measures 2030 gender index 2019 report, suggests that gender inequalities continue to persist globally (Sen, 2019). This report indicated that no country was on track to achieve gender equality by 2030 , the UN deadline to achieve its SDGs and gave Ireland a rating of "poor" under SDG 5, the SDG specifically attributed to Gender Equality (Equal Measures 2030, 2019).

In recent years, senior leadership within the Irish Permanent Defence Forces (PDF) have been actively engaged in promoting gender equality within the organisation. For some, there is a discourse that gender equality exists, that all opportunities are equally open to both men and women, and that promotion is based purely on merit. However, women within the Irish Naval Service (NS), a subsection of the PDF, currently account for under 7 per cent of serving members, and up until 2020 were only represented up to the rank of Lieutenant Commander (OF-3), at officer level, and Petty Officer (OR-5) at other ranks level ${ }^{1}$. In 2020, the NS promoted its first women to the rank of Commander (OF-4) and Chief Petty Officer (OR-6). This resonates with one of the key challenges identified in Ireland's National Strategy for Women and Girls 2017-2020, that is, "a mistaken impression that women's equality has been achieved" (Department of Justice, 2017, p.17). This only serves to remove all focus and attention from these issues that still need addressing

Gender inequality is a complex topic and cannot be attributed to a single cause. However, it is important to try identifying possible causes so that they can be addressed. Research suggests that some gender inequalities result from certain prejudiced beliefs that are deeply embedded within society and organisational culture. Consequently, these can create significant barriers for women in the workplace, particularly at higher positions of power. (Martin \& Barnard, 2013; Tennant, 2017; Akinlolu \& Haupt, 2020). Redfern (2007) posits that our language and society reflect one another. Robinson and Giles further argue that "investigating the creation and meaning in language and social interaction will allow us to identify current discursive practices that create, promote or maintain inequality" (2001, p.457). Therefore, the focus of this article will be centred on the language used in the NS and an exploration of relationship between this language, stereotypes, and gender inequality.

This article aims to explore whether the words we use can harm us. More specifically, if linguistic bias within everyday language use is causing gender discrimination in the NS, with the broader intention of contributing to agendas about equality and inclusion. The research strategy will be built on Beukeboom and Burgers' (2019) Social Categories and Stereotypes Communication (SCSC) framework.

The relevance of this research to the PDF can be demonstrated through assisting the organisation to meet its obligations and commitments with respect to gender equality. The PDF state that they "are committed to gender equality" (Irish Defence Forces, n.d.). In the White Paper on Defence 2015, and its recent 2019 update, the PDF committed to increasing female participation at all ranks within the PDF and to double female participation within the organisation from 6 per cent to 12 per cent by 2023 (Department of Defence, 2015; Department of Defence, 2019). It also committed to identifying any impediments to the advancement of women in the PDF.

\footnotetext{
${ }^{1}$ NATO grading for Officer (OF) and Non-Officer (OR) personnel, scaled from 1-10 for Officers and 1-9 for NonOfficers. In the PDF, the highest naval officer rank is OF-8 and naval non-officer rank is OR-9.
} 
Under Ireland's third National Action Plan for the implementation of UNSCR 1325 and the National Strategy for Women and Girls, the PDF is obligated to increase the participation of women at senior decision making and leadership level, increase understanding of the "impact of harmful social norms, including masculinities and discriminatory gender norms on gender equality" and, address the "effects and drivers of harmful masculinities and discriminatory gender norms" (Department of Foreign Affairs, 2019, p.29). It is believed this study can assist the PDF in their endeavours to meet these commitments and obligations.

\title{
PART ONE. Literature Review
}

\author{
Man is defined as a human being and woman as a female - whenever she behaves as a human \\ being, she is said to imitate the male.
}

(Simone de Beauvoir,1989)

This review aims to develop a solid theoretical foundation for the article by establishing and critically reviewing the key concepts and theories that will inform it. Beukeboom and Burgers' (2019) Social Categories and Stereotypes Communications (SCSC) framework will provide the theoretical framework that guides the research. However, before discussing the SCSC framework, this review will first explore several foundational concepts that form the basis for the framework, mainly stereotypes, social categories, prejudice and discrimination, and linguistic biases. The focus for the research will be carried out mainly from a gender perspective.

The SCSC framework provides an integrative framework that illustrates how everyday language both creates and maintains stereotypes and social categories. This can inevitably lead to discrimination (Beukeboom \& Burgers, 2019). According to Lilienfield (2017), some critics have voiced apprehensions about research around language and social psychology. Such critics state that it fosters a culture of political correctness (Sunstein, 2015) or that it discourages or suppresses controversial or unpopular speech (Lukianoff \& Haidt, 2015). However, these arguments, although considered valid, focus on negative second and third order effects of the research on the status quo, without paying due consideration to the negative effects that already exist. Lilienfield proposes that these critics are committing the "arguments from adverse consequences fallacy" (2017, p.150). They are concluding that the research is flawed simply because it can produce negative real-world outcomes (Sagan, 1995; Lilienfield, 2017). Taylor and Usborne propose that language offers an understanding of social behaviours "beyond what has been revealed through a mainstream social psychology analysis of discrimination" (2007, p.204).

Until recently, much of the literature around gender and language focused on areas of dominance and difference in speech acts, and the contrasting communicative styles that result (Sheridan, 2007). In Robin Lakoff's (1973) influential book, Language and Woman's Place, she focused on the difference in speech patterns between men and women. She highlights that women use less assertive language through hedges and men dominant speech by interrupting women more than they do other men (Sheridan, 2007). Robinson and Giles (2001) argue that studying language, and more specifically talk, in this manner decontextualizes it and focuses solely on the mechanical features of talk. To clarify this point, they highlight that when analysing speech interruptions, although easy to analyse, the researcher fails to consider the meaning of 
the interruption to the interlocutor. Although studies and research in this area of gender and language have validity, they "treat sexist talk as a linguistic rather than as a social and contextual problem, ignoring the context sensitivity of the actual language use" (Cameron, 1995, cited in Speer, 2005, p.3). Therefore, they are not appropriate to this study and have been excluded. The next section analyses key theories and concepts surrounding stereotypes and social categories that underlie this study.

\section{Social Categories, Stereotypes and Social Norms}

In March 2020, the United Nations Development Programme (UNDP) published a report on the first conducted Gender Social Norm Index (GNSI). This comprehensive report analysed data from 75 countries that collectively contain more than 80 per cent of the global population. It found that almost 90 per cent of people are biased against women (UNDP, 2020). Pedro Conceiçao, the director of UNDP's Human Development Report Office stated in an article published by the Guardian newspaper, that "the data shows that the perception and expectations in society about the role of women are prejudiced against them" (Ford, 2020, p.7). To understand why these prejudices and inequalities still exist, after so much global investment into gender equality, having a foundational knowledge of social categories, stereotypes and social norms is key (Beukeboom \& Burgers, 2017).

The grouping or categorising of people based on similar characteristics, such as gender, age or ethnicity is an innate and mostly unconscious human tendency (Beukeboom \& Burgers, 2019). Allport (1954) contends that doing so, allows use of previously stored knowledge to go beyond the information given to better understand a complex environment. Social categories are heterogeneous and multi-dimensional. They can be hugely influenced by society, context, organisational culture etc. Once an individual is categorised into a social category, there is a tendency to view them more as a member of that group rather than as an individual (Banton, 2011). Thus, the behaviours, characteristics or traits of that group are associated to them, this is known as stereotyping (Brannon, 2017). A set of accepted standards of behaviour, known as social norms, are also associated with the group. These stereotypes and social norms become part of the social category knowledge that people store. Social categories, stereotypes, and social norms are all interrelated, and each can influence the other. For instance, people attending university would normally be categorised as "students". Some of the stereotypes attributed with students are that they are poor, lazy, and they love to party. Social norms associated with this group are that they go out on weeknights and consume a lot of alcohol.

This cognitive process of categorising is automatic and mostly unconscious. Although it can be useful for making quick evaluations, it is an overly simplistic and flawed process. Over reliance on this process can lead to a wholly inaccurate representation of a person due to the application of generalised stereotypic beliefs rather than using the individuating information that is available (Hinton, 2017). This miscalculation can lead to prejudice and discrimination. Research has illustrated further consequences of relying on social categories and stereotypes. People tend to exaggerate the similarities between individuals of the same group, thus reducing the individuality of members of that social category (Allport, 1954; Beukeboom \& Burgers, 2019). An abundance of research has confirmed that social categories, stereotypes, and social norms have a pervasive and fundamental role in social perception, judgment, and interaction 
(Beukeboom \& Burgers, 2017; Garcia-Ael et al, 2018; Fox, 2019). This is particularly obvious in social categories based on gender.

Gender is a social construct that associates certain attributes or roles to men and women, many of which are considered binary (UNDP, 2020). Social role theory can provide a theoretical explanation for this social construct (Horvath et al, 2016). Social role theory is premised on the principle that gender stereotypes are constructs influenced by the perceived and actual roles women and men occupy in society (Wood \& Eagly, 2011). To clarify, when women or men are observed to be dominant in a particular occupation, for example, nursing for women or the military for men, then this is perceived to be the norm. An inference subsequently occurs that the binary stereotypical traits associated with that gender are the reasons for that norm. Women are more caring and therefore more suited to nursing or men are physically strong and therefore more suited to the military. These traits now become synonymous with these roles and the social categories of the individuals who occupy them (Horvath et al, 2016), thereby creating and maintaining gender related expectations for that occupation (Sheridan, 2007). These gendered socialisations, which are reproduced through generations, directly shape the understanding and perception of masculinity and femininity, as well as the stereotypes and social norms associated with these gendered social categories (Zosuls et al, 2011; Oxford, 2019). Horvath et al, (2016) maintain that these perceptions ensure a gender hierarchy, that ascribes men and masculinity a higher status, continues to be widely prevalent. Up until recently, Irish society was predominantly, if not exclusively, influenced by male patriarchal structures, and with women still underrepresented in positions of power and influence, it could be argued that Irish society is still strongly influenced by male patriarchal structures (Sheehan et al, 2017). Considering the long history of male hegemony in Irish society, Griffin (2019) states that attitudes about gender roles and a gender hierarchy of inherent male superiority, have been deeply socialised in the Irish psyche. Therefore, women in Ireland, particularly in male dominated organisations, can experience challenges and barriers that emanate from these engrained beliefs (Martin \& Barnard, 2013). The UNDP GSNI report found that

Women often face strong conventional societal expectations to be caregivers; men are expected to be breadwinners. Embedded in these social norms are longstanding patterns of exclusion from household and community decision making that limit women's opportunities and choices. (UNDP, 2020, p.6)

Considering the military is a very male dominated organisation, it should be no surprise that military culture has been found to reinforce a hyper masculine identity stereotype (Archer, 2012). Garcia-Ael et al, (2018), contend that these gender stereotypes and ideologies firmly establish male dominance in the workplace, and have been deduced to be responsible for the persistent gender inequalities that exist. Archer further reiterates this by stating that "gendered stereotypes in the US military context often result in the creation of barriers for women" (2012, p.359).

As outlined, gender social categories, stereotypes, and social norms can create gender inequalities, or what could be considered discrimination. Beukeboom and Burgers explain that discrimination occurs when an individual or a group is "treated, described and/or judged based on generic social category associations rather than individuating information" (2019, p.5). Prejudice and discrimination are intricately intertwined with social categories and social norms. Figure 1 illustrates that when an individual is categorised, activation of a stereotype or prejudice 
or both will occur. However, it also illustrates, that the activation of a stereotype or prejudice does not, guarantee the application of discrimination. The application of discrimination is dependent on several other contextual factors such as intent, effort and cognitive capacity (Cralley \& Ruscher, 2005; Beukeboom \& Burgers, 2019).

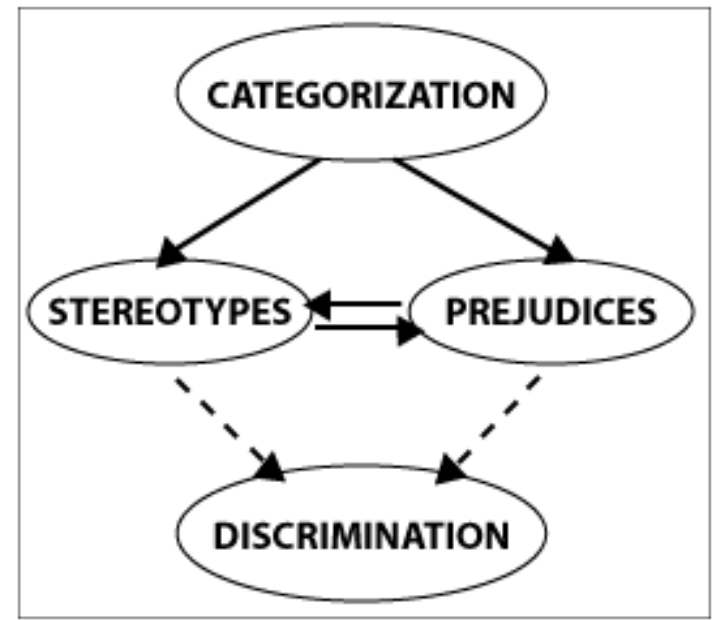

Figure 1- Illustrative of Relationship between Stereotype, Prejudice and Discrimination (Swim, 2007)

Social approval and disapproval are extremely powerful constructs which maintain these stereotypical beliefs. They can often guide actions which lead to societal acceptance of overt discrimination of individuals who do not conform to the stereotypes and social norms of their group. The Magdalene Laundries in Ireland provide a particularly reprehensible example to demonstrate just how powerful societal expectations, approval and disapproval can be. The Magdalene Laundries were institutions, usually run by the Catholic Church, for women and girls who were unmarried mothers, considered to be "promiscuous", sexually abused or had grown up in the care of the Church and State (Justice for Magdalene Research, n.d.). These women and girls "were imprisoned, forced to carry out unpaid labour and subjected to severe psychological and physical maltreatment" (Justice for Magdalene Research, n.d.). For over two centuries, there was widespread societal acceptance of the human rights violations experienced by women who did not conform to the social norm allowing them to only have intercourse or children inside wedlock. This example also demonstrates the inequality in the treatment of the women involved in procreating outside of wedlock because the same treatment was not applied to the men involved. Therefore, gender-based discriminations and gender stereotypes can have a pernicious way of reinforcing existing gender hierarchies and maintaining gender inequalities (Smith et al, 2019; Oxford, 2019).

Although it is possible to generally identify the main causes and effects of gender discrimination, the difficult challenge is pointing precisely to how these systemic gender inequalities are operating and being maintained. This was acknowledged in the UNDP GSNI (UNDP, 2020) report with it questioning if there were hidden dimensions to gender equality? In the next section, how social categories and stereotypes are communicated will be explored.

\section{Linguistic Bias}

Language is the embodiment of culture and it is the medium through which most interactions are conducted (Wang, 2016). Therefore, it follows that it "plays a crucial role in the 
consensualisation of stereotypes within cultural groups" (Beukeboom \& Burgers, 2019, p.1). Augoustinos and Every (2007) argue that by analysing everyday conversations it was possible to confirm the existence of social inequalities and how these could be linked to stereotypes. A person's choice of language or linguistic form can communicate non-linguistic social information. When describing a person, linguistic choice can communicate that certain stereotypical beliefs should be inferred about that individual (Holmes, 1992). For example, referring to a professional woman as a girl communicates that youth and immaturity, among other things, should be inferred about the woman. This is an example of what is known as a linguistic bias.

Burgers and Beukeboom define a linguistic bias as a

systematic asymmetry in word choice as a function of the social category - and its associated stereotypic expectancies - to which the target belongs (2016, p.416).

Linguistic biases can take numerous forms and manifest linguistically in different ways (Beukeboom \& Burgers, 2019). The next sections will examine some of these linguistic biases, particularly those in linguistic labelling, communication content and choice of linguistic form.

\section{Linguistic Labelling}

Labels are specific words that are used to denote a social category (Beukeboom \& Burgers, 2017). They are inherently linked with stereotypes because their function is to carry meaning about a social group and its members, and when used stereotype formation becomes more likely (Tennant, 2017). Labels reflect existing social category cognitions, some of which may be unique to an individual culture. For example, in the NS there are labels associated with different branches such as "The Black Gang", "Dustys", "Deck Apes" each of which provide information about the people in those categories.

Labels, generally, fall into two categories: category labels and derogatory labels (Hedger, 2013). Category labels are used to denote group membership whereas derogatory labels are used to degrade individuals. For instance, a category label might be "Homosexual", whereas a derogatory label for this person would be 'Fag' (Tennant, 2017). Carnaghi and Maass' (2007) research demonstrated that derogatory labels elicit a more negative representation of an individual than category labels. Derogatory Gender Labels (DGLS) are a subcategory of derogatory labels dealing specifically with gender. Beukeboom and Burgers maintain that DGLS are used to degrade women by "conveying hostile stereotypic expectancies about women, while simultaneously conveying negative affect" (2019, p.13). While DGLs present biases, prejudice and discrimination in an overt manner, category labels can appear innocuous. However, as Wetherell and Potter (1992) highlight, language does not have to be explicitly sexist for it to have effects that are oppressive, exclusionary, and discriminatory in nature. Category labels have a lot of power to transmit, maintain and reinforce stereotypes (Maass, 1999). The labels career woman or family man illustrate this point. Both these labels appear to be benign. However, there are no male or female equivalent to them (career man or family woman) because these gender roles are well established as the norm. Hence, it is implied that a man has a career and a woman has a family. Therefore, by using the labels career woman and family man, the established gender roles are being transmitted, confirmed, and reinforced. 
Augoustinos and Every (2007) assert that labels can be used to define very specific boundaries for a group. These can have a very powerful effect of justifying and legitimising negative and discriminatory behaviour towards people in that group. Referring to the example used earlier of the Magdalene Laundries, the labelling of the women as "fallen women", "Maggies" or "prostitutes" assisted in the societal acceptance of how they were treated. Moncrieffe and Eyben (2013) postulate that the type of label used may call for, and justify particular responses, or even policies for dealing with the individuals from the category. This may explain the collusion of the Irish State in the Magdalene Laundries (McDonald, 2013). Labels can illustrate the hierarchy and social power that exists. This is apparent in the use of generics and in the asymmetry that exists between labels of different social categories.

Generics are the use of non-inclusive collective terms to describe a collective, for example, the use of the word "Army" as a collective term to describe the PDF. The problem this creates is that it is misrepresentative of the group and can lead people to affirm the consequent, that is, that the Army is the PDF therefore the PDF is the Army. This consequently biases mental representations of the PDF, resulting in the NS and Air Corps being rendered invisible. In the English language, Army is not a generic term for military, it may be synonymous with it but so too is Navy and Air Corps. Therefore, the ubiquitous use of it as a generic term in the PDF is socially constructed and embedded in the culture of the PDF organisation. This is very similar to the use of masculine generics, that is, the use of masculine terms to universally describe men, men and women and groups where gender is unknown or irrelevant (Horvath et al, 2016). English is a genderless language, so the use of masculine generics is also a social construct. It is premised on the ideology of "inclusivity" and equal representation but just like in the example provided above, all men may be people but all people are not men (Menegatti \& Rubini, 2017; Tennant, 2017). An abundance of research has clearly demonstrated that the use of male generics elicits a male bias in mental representations and renders women invisible (Stout \& Dasgupta,2011; Horvath et al, 2016). Oxford claims that the "universal masculine" erases women from text so that in public policy or history women do not exist (2019, p.1031).

By privileging one category to describe a collective of categories it creates a perception that that category is the prototype, or the norm and other categories should be compared to it (Menegatti \& Rubini, 2017). When a category is privileged as the referent group of comparison, status inequalities are perceived as more legitimated (Menegatti \& Rubini, 2017). This can be seen when, because of masculine generics, the explicit marking of sex occurs, for example describing a doctor as a 'female' doctor. Tennant (2017) states that the term female is used as a label with limiting criteria. Semin (2012) contends that a single word, or label, can have a profound and powerful effect in directing the focus of a conversation or marginalising the topic of conversation. Aronoff and Rees (2017) further contend that when the label used is from the explicit marking of sex, women remain extra visible as women but invisible as people or professionals. To demonstrate this point, Robinson and Giles (2001) advance that governments marginalise discrimination and violence against women by describing them as "women's issues" which are thus distinct from "human rights issues". This is just one example of the gender asymmetries that exists in linguistic labelling.

Other asymmetries include a lack of terms referring to women in the English vocabulary, for example, fireman, chairman and anchor-man have no female equivalents (Menegatti \& Rubini, 2017). When there are female equivalents, Eckert and McConnell-Ginnet (2003) 
contend that these equivalents commonly undergo "semantic derogation and sexualisation" (Lan \& Jingxia, 2019). There are many examples that demonstrate this, for example, Master and Mistress, Governor and Governess, Sir and Madam. As Eckert and McConnell-Ginnet explain "mistress semantically connotes a sexualised female while master semantically refers to positivity and power" (2003, p.3). The male list speaks of power and high status, whereas the female list has a very different set of connotations (Shariatmadari, 2019). However, this phenomenon is not just isolated to female equivalents of male word. Many words used to describe women have become pejorative terms over the years, thereby resulting in far more DGLs for females than for males (Sutton, 2010). For example, the term slut originally described a kitchen maid or a sloppy woman (Westcott, 2011). This is far removed from the negative connotations that are associated with the term today. Sunderland (cited in Westcott, 2011) identified a spike in the use of the term in the early 1920's and in the 1980's which she correlated to increases in women's independence during these times. She surmises that the spike in the use of the derogatory term may be attributed to women encroaching on areas that men were used to dominating (Westcott, 2011).

These asymmetries provide insights into the biasing of status and power into men's favour. However, biases do not just occur in how social categories are labelled but also in how people of those categories are talked about once labelled (Beukeboom \& Burgers, 2019). In the succeeding sections, biases in communication content and the choice of linguistic form will be examined.

\section{Communication Content}

Once labelled, evidence suggests, that stereotype formation and association of categorised individuals becomes more prevalent. There is an expectancy for individuals to display behaviours and traits that are consistent with the stereotypical beliefs of that category, that is, stereotypical consistent behaviour (Burgers \& Beukeboom, 2016). Beukeboom and Burgers (2019) deduce that when categorised individuals are communicated about, it is predominantly using stereotype confirming information associated to that category, rather than individuating information. For example, conversations about Stuart Barnes, the former English rugby player and current rugby commentator, are predominantly about his rugby career and rarely about his history degree from Oxford University. This general tendency to, systematically and predominantly, communicate stereotype confirming information about categorised individuals reinforces and maintains stereotype knowledge about that category by continuously drawing attention to these stereotypes (Collins \& Clément, 2012). For example, an adult woman becoming pregnant is quite a common occurrence, but it should not automatically lead to the assumption that all adult women will become pregnant. In the NS, a woman's pregnancy, for medical reasons, results in them being unavailable for sea-going duties. The more that serving women become pregnant, the more this information and its association with unavailability for sea-going duties is likely to be discussed within the organisation. This may lead to a stereotypic assumption that women choose to get pregnant to avoid sea-going duties. By repeatedly retelling this stereotypic representation, it can thus become a widely shared cultural belief within the organisation. Menegatti and Rubini state,

Given that language not only reflects stereotypical beliefs but also affects recipients' cognition and behaviour, the use of expressions consistent with gender stereotypes 
contributes to transmit and reinforce such belief system and can produce actual discrimination against women" $(2017$, p.2)

However, it is not just the type of information that is communicated about categorised individuals that is problematic but also how that information is communicated, that is, the lexical choices people make in everyday communications. This concept will be explored in the next section.

\section{Linguistic Form}

Burgers and Beukeboom observe that people "systematically vary their language when communicating stereotype consistent and inconsistent behaviour" (2016, p.414) and these variations have important communicative consequences. The speaker's language variation not only conveys their own biases and assumptions, but it transmits bias to receivers, ultimately reinforcing stereotypes in the wider society (Van Dijk, 1987). There are several subtle ways that a person can reveal their stereotype beliefs by the linguistic forms they use. The most studied of these is the use of abstraction (Semin, 2012).

Abstraction is concerned with the varying levels of detail our descriptions portray. They span from very low levels of abstraction, known as concrete descriptions to high levels of abstraction, known as abstract descriptions (Douglas \& Sutton, 2003). By choosing terms at different levels of abstraction when describing a person, it is possible to affect how the receiver attributes behaviours to that person in a way that is consistent with their stereotypical beliefs. (Menegatti \& Rubini, 2017). A concrete description provides very specific details and is very much context dependent, whereas abstract descriptions provide more information about the person's dispositional qualities and less information about the specific situation (Semin \& Fiedler, 1988). For example, a concrete description of an event might be John hit Mark, whereas an abstract description of the same event would be John is aggressive. Abstract terms infer that it is a person's disposition that causes their behaviour (internal attribution), whereas concrete terms infer that the situation is the cause of their behaviour (external attribution) (Wigboldus et al, 2000). The relevance of abstraction to stereotype maintenance and reinforcement is that when abstract terms are used to describe stereotypical expected behaviour, they endorse existing stereotypic beliefs by attributing the behaviour they are describing to a person's disposition rather than using situation information (Maass et al, 1999). The more abstract the description the more recipients of the description will have the ability to gain meaning from things that are not said. When abstract terms are used to describe an event, it is harder to falsify or disprove the description of the event, for example it is not possible to disprove whether John is aggressive, but it is possible to disprove that John hit Mark, if this is not what happened.

The Linguistic Category Model (LCM) provides a tool to measure the levels of abstraction used in interpersonal language (Semin, 2012). It provides a taxonomy of linguistic categories on which to evaluate the level of abstraction by categorising word types on a spectrum from most abstract to most concrete, see Figure 2 below. Descriptive Action Verbs (DAVs) being the most concrete and adjectives the most abstract. 


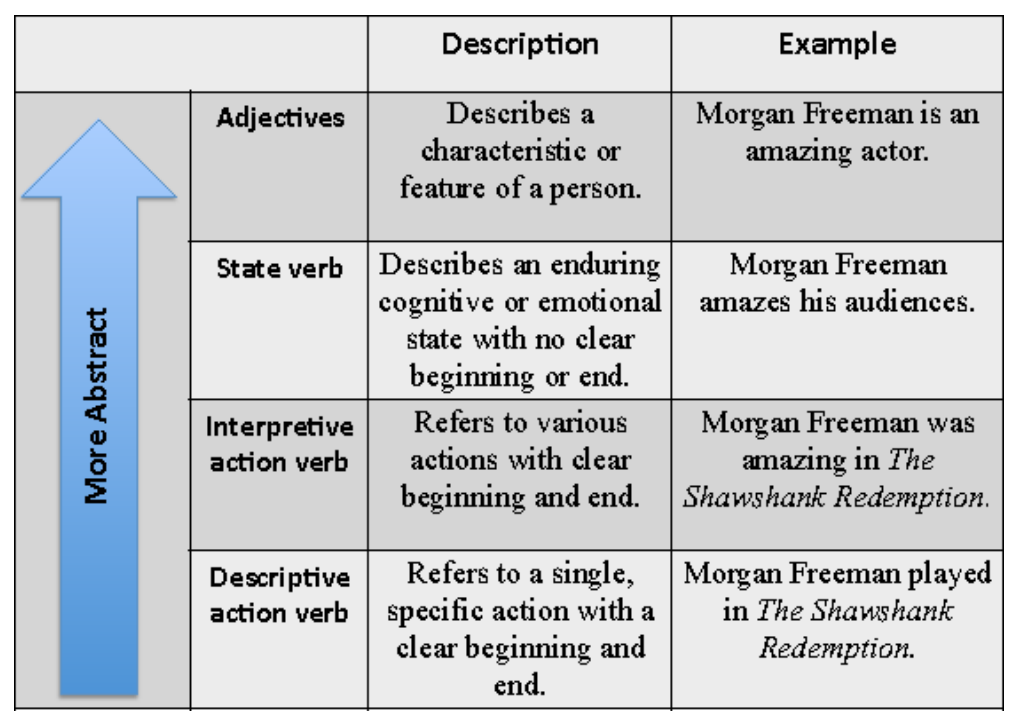

Figure 2 - Linguistic Categories Model (Otterbacher, 2015)

Although each of the LCM classifications will provide similar descriptions of an event, Semin (2012) asserts that they will each create a different representation of that event, and that a single word can have a powerful effect in causing listeners to "zoom in" or "zoom out" on the traits and behaviours of the categorised individual. The LCM forms the basis for several linguistic mechanisms that underlie the communication of stereotypes, most notably the Linguistic Expectancy Bias (LEB) and the Linguistic Intergroup Bias (LIB).

LEB is premised on the theory that people will use more concrete descriptive language when describing behaviours that are not stereotypically expected, but will use more abstract language when describing stereotypically expected behaviours (Wigboldus et al, 2000, Ng, 2007). When behaviours are stereotypically consistent, using abstract descriptions causes people to draw on their stored social category knowledge and depict their own mental representation of the event.

LEB focuses on the level of language abstraction as a function of expectancy of a stereotype behaviour whereas LIB takes into account the role the desirability of the behaviour and intergroup dynamics will have on the level of abstraction (Semin, 2012). LIB is premised on the theory that people will tend to use more abstract language to describe desirable behaviours of in-group members and undesirable behaviours of out-group members and more concrete language to describe undesirable behaviours of in-group members and desirable behaviours of out-group members vice versa (Collins \& Clément, 2012). Augoustinos and Every (2007) explain that this pattern of positive self-presentation and negative other presentation creates a more favourable portrait of the in-group thus protecting its dominance and reinforcing the hierarchy.

Another form of linguistic bias that focuses on the description of stereotype behaviours, but is not premised on the LCM, is that of Stereotype Explanation Bias (SEB) (Beukeboom, 2012). SEB is the tendency to provide an explanation for behaviours that are not consistent with the social category's stereotype expectancy, thereby providing external attribution for the behaviour.

Having considered and discussed some of the most prominent forms of bias that occurs in interpersonal language, Beukeboom and Burgers' (2019) SCSC framework will now be used 
to demonstrate how language can create a self-perpetuating cycle that maintains and reinforces stereotypes.

\section{Social Categories and Stereotype Communication (SCSC) Framework}

Beukeboom and Burgers' (2019) SCSC framework combines several fields, which have predominantly been studied independently, into a comprehensive framework that provides a greater understanding of how linguistic biases produce a self-perpetuating cycle of stereotype maintenance. The SCSC framework, see Figure 3, is made up of three main parts which influence each other to varying degrees. These are the target's situation, (stored) social category cognition, and communicative context.

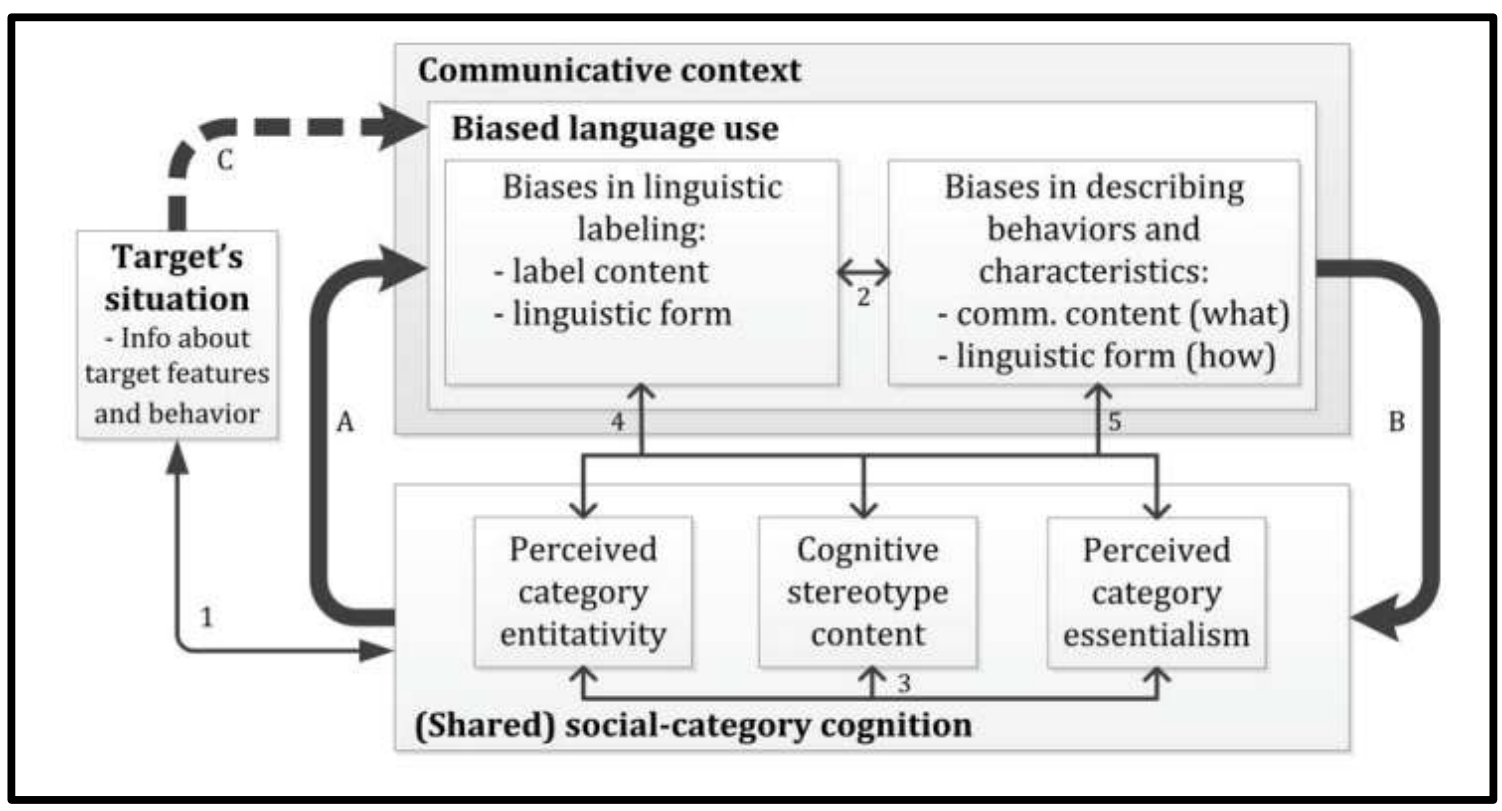

Figure 3 - The SCSC Framework (Beukeboom \& Burgers, 2019, p.6)

The first of these parts, target situation, is concerned with the individuating information that is available about the target and the situation they are in. The second part, (shared) social category cognition has three fundamental and reciprocally related variables which directly influence the formation and use of social category stereotypes. Beukeboom and Burgers describe these as:

Perceived category entitativity is the extent in which a category is perceived as a meaningful, unified and coherent group.

Cognitive stereotype content is the content of the cognitive representation people hold about a social category, consisting of beliefs and expectancies about probable behaviours, features and traits.

Perceived category essentialism refers to the extent in which an associated set of characteristics is perceived to be immutable to its members, and stable across time and situations. (2019, p9-10)

Finally, the communicative context is concerned with linguistic labelling, communication content and linguistic form, all of which have been discussed in previous sections. Referring to Figure 3, Arrow A illustrates how the stereotypic beliefs and expectancies that are held about a 
social category will be reflected in the biased language used when describing a categorised individual. The pervasiveness of the biased language will be dependent on the strength of the shared category cognition which is influenced by the three fundamental variables discussed above. Arrow B illustrates that these linguistic biases, in turn, feed the social category cognition by sharing and confirming these existing stereotypic views. Arrow $C$ illustrates the level of which the targets situation is discussed in the description of them. It is a hashed line because this level varies. As discussed previously, abstract descriptions will provide no link to the target's situation, whereas concrete descriptions will provide a definitive link to their situation. Lines 15 take a more in depth look at the relationships that exist between the framework's subcategories and are beyond the scope of this thesis to discuss in any detail.

Although this framework demonstrates how language influences bias and how bias influences language, it does not examine the effects this has on the target. Therefore, to further this research, the effects this language, if it exists in the NS, is currently having on women in the NS will be explored. The next chapter will outline how this will be achieved.

Gender stereotypes, and the consequent gender bias that results from them, are prevalent in today's society, as evidenced by the UNDP's GSNI report which found that nine out every ten people are biased against women (UNDP, 2020). Anti-sexism norms are increasing, and overt displays of sexist discrimination are decreasing, yet gender inequality and bias persist in a prevalent manner (Collins \& Clément, 2012). Why is this the case? Language provides a means to transmit and carry cognition, therefore an examination of language, particularly, the lexical and conceptual semantics of language, can provide an insight why gender inequality is still so prevalent (Collins \& Clément, 2012).

Collins and Clément postulate that "language is a powerful force in the perpetuation of inequality and discrimination" (2012, p.377) and that it provides a means to enact these in more subtle forms. As Wetherell and Potter (1992) argue, language does not have to be explicitly sexist for it to have effects that are oppressive, exclusionary, and discriminatory in nature. They further point out that subtle forms of discrimination, for example linguistic biases, can be more pervasive since both the intent of the speaker and the actual discriminatory act can be extremely hard to pin down. Menegetti and Rubini posit that gender bias and sexism is so "embedded in the grammatical structure of language" $(2017$, p.8) that linguistic biases are perceived as being normative, thereby allowing gender bias and discrimination to prevail simply by people following communication rules ( $\mathrm{Ng}, 2007)$.

Linguistic biases work on the premise that language is used differently in situations where stereotype behaviours are confirmed or consistent with beliefs and where stereotype behaviours are violated or inconsistent with beliefs (Maass et al, 1989). Language variations are also dependent on the group status of the person they are speaking to or about. The subtle changes and variations in language, associated with linguistic biases, can have an,

unyielding transformative effect, changing what it carries and distorting the perception of those who are exposed to it, thus influencing prejudice by activating culturally shared ideas and creating implicit expectations that subtly transform the perception of groups and group members. (Collins \& Clément, 2012, p.383) 
Beukeboom et al, argue that a person's word choice and their linguistic use are not arbitrary, but driven by "systematic and implicit social cognitive processes" (2010, p.978). Therefore, surveying the use and type of language being used in the workplace will provide an opportunity to identify if a culture of subtle discrimination exists. Beukeboom and Burger's (2019) SCSC framework examines word choice and linguistic use, in conjunction with stereotypes, social categories and cognition. It provides a comprehensive model which demonstrates how language influences cognition and cognition influences language. This provides a plausible explanation of how the gender bias discrimination still exist despite the increase in social norms inhibiting overt expressions of sexism (Collins \& Clément, 2012).

If gender inequality is to be eradicated, then gender stereotypes and myths need to be dispelled. Robinson and Giles believe that this can be achieved by "deconstructing them and showing the processes by which language can be used to create or maintain inequality" (2001, p.457). They further claim that by examining language, it is possible to "move beyond the immediate research situation to the examination of the real social consequences of discursive constructions" (Robinson \& Giles, 2001, p.459).

\section{PART TWO. Research Methodology}

Gender equality is a human fight, not a female fight.

(Frieda Pinto, 2015)

The research question sought to explore linguistic biases in the NS and to examine their effect on gender equality. Therefore, purposive sampling was used. The data collection methods used were as follows:

- A linguistic bias survey, open to all members of the NS.

- Critical incident reports conducted by women in NS with more than 15 years' service.

The survey was of mixed methods embedded research design to enhance the overall design. It contained a mixture of qualitative open questions and quantitative closed questions. The quantitative questions were used to establish the existence of gender linguistic bias and to provide demographic data that would assist with the qualitative analysis of the survey and to identify how prevalent this phenomenon was within the organisation. There were several reasons why this method was chosen, mainly it was an excellent way to establish if gender stereotype biases and linguistic biases existed in the NS, while maintaining anonymity of participants. The surveys were first transcribed to provide some familiarity with possible themes in them. The transcriptions were then inputted into an excel worksheet and this allowed for quantitative analysis which assisted in identifying themes. However, to fully explore the richness of the data the decision was taken to confine the discussion to the themes that correlated most to the literature review and provided the most insight to answer the research question were selected.

The second method used was the analysis of critical incident reports. This method was selected to establish how exposed women were to gender biased language, their level of awareness of it and what negative effects they felt it had on their equality. Therefore, a 
purposive sample of women in the NS was selected, all of whom had a minimum of fifteen years' service. The data from the critical incident reports was cleaned, chunked, and coded before comparing similarity of themes with the survey findings.

\section{PART THREE. Research Findings}

This part will present the findings and analysis of the data collected from the survey responses and the critical incident reports, and begins with analysis of the surveys. The survey was used to assess the existence and prevalence of gender stereotypes and gender biased language in the NS. Therefore, key themes and trends that demonstrate this will be identified and explored. This is followed by the presentation of analysis and findings from the critical incident reports. Reflecting on the trends identified in the survey analysis, these findings will be presented in a manner that illustrates the consequences gender stereotypes and gender biased language have on gender equality. Several tables, graphs, and vignettes, taken from the survey responses and critical incident reports, will be used to illustrate and add depth to the interpretation of these findings.

\section{Survey Analysis}

With the aim of establishing and assessing gender stereotypes and gender biased language, the survey comprised of a mixture of open and closed questions, presenting participants with statements, labels, and pictures that either conformed to stereotypical beliefs about gender or not. Responses were analysed to identify trends that were either consistent or inconsistent with the theories outlined in the Literature Review. The findings of this analysis will be presented and discussed below under the headings of stereotypes, labels, and language variations.

\section{Stereotypes}

Table 1 below provides a summary of the behaviours, traits and roles that were included in the survey, which are divided into categories as per stereotype expectancy.

Table 1 - Behaviours, traits and roles in survey and their corresponding stereotype expectancy

\begin{tabular}{|c|c|c|c|c|}
\hline \multirow{2}{*}{$\begin{array}{c}\text { Gender } \\
\text { Association }\end{array}$} & \multicolumn{2}{|c|}{ Stereotypically Expected } & \multicolumn{2}{|c|}{ Stereotypically Unexpected } \\
\hline & Negative & Positive & Negative & Positive \\
\hline Female & $\begin{array}{ll}\text { - } & \text { Gossip } \\
\text { - } & \text { Slut } \\
\text { - } & \text { Emotional } \\
\text { - } & \text { Ballbreaker }\end{array}$ & - Helping & - Littering & - Pilot \\
\hline Male & $\begin{array}{ll}\text { - } & \text { Fighting } \\
\text { - } & \text { Arrogant } \\
\text { - } & \text { Creep } \\
\text { - } & \text { Asshole }\end{array}$ & - Successful & - Crying & - Nurse \\
\hline
\end{tabular}


83 per cent of respondents ${ }^{2}$ returned answers which were consistent with stereotype expectancy. This suggests that gender stereotypes are relatively active in the classification of images and labels. One could say, therefore, that NS personnel rely on their stored stereotype knowledge when assessing men and women. Eagly et al (2000) state that the content of gender stereotypes is not neutral. They reflect an asymmetry of status and power in favour of men, which are attached to the corresponding gender roles. Therefore, gender roles will be examined first.

As previously discussed, gender roles refer to what is seen as appropriate behaviours for men and women in society. Participants were asked to describe pictures in which the gender roles were reversed (see Figure 5, a woman as a pilot and a man as a nurse).

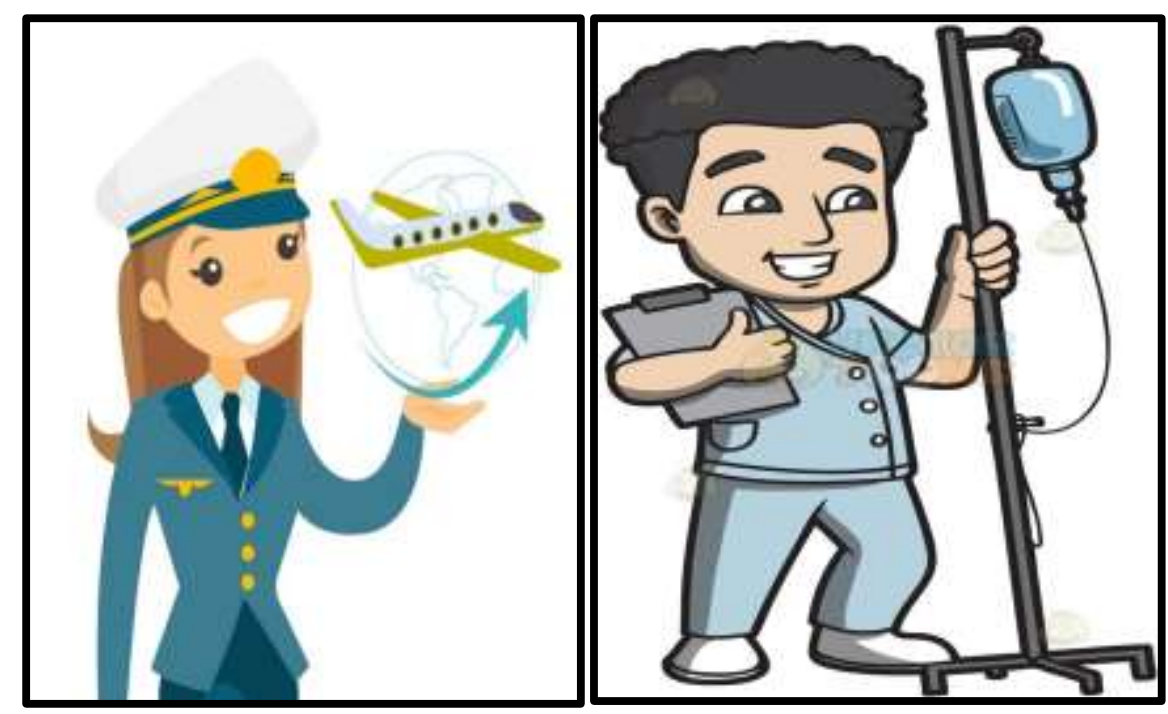

Figure 4-Gender Role Pictures in Survey

If gender role beliefs are active, then participants will relate descriptions which assign a lower value to the woman's occupation or mark it as different in some way. Therefore, descriptions were analysed to identify the following:

- The main referent in the descriptions

- The occupations assigned to the man and woman

- If the role portrayed in either picture was marked as different in some way

Findings, illustrated in Figure 6, supported the notion that gender roles are active.

\footnotetext{
2 The only outliers in the data analysis that did not fully conform to this table were:

- Inconclusive result for 'successful'

- Lower than expected negative and female association with 'emotional'

- Lower than expected male association with 'arrogant' and 'asshole', and female association with 'ballbreaker'
} 


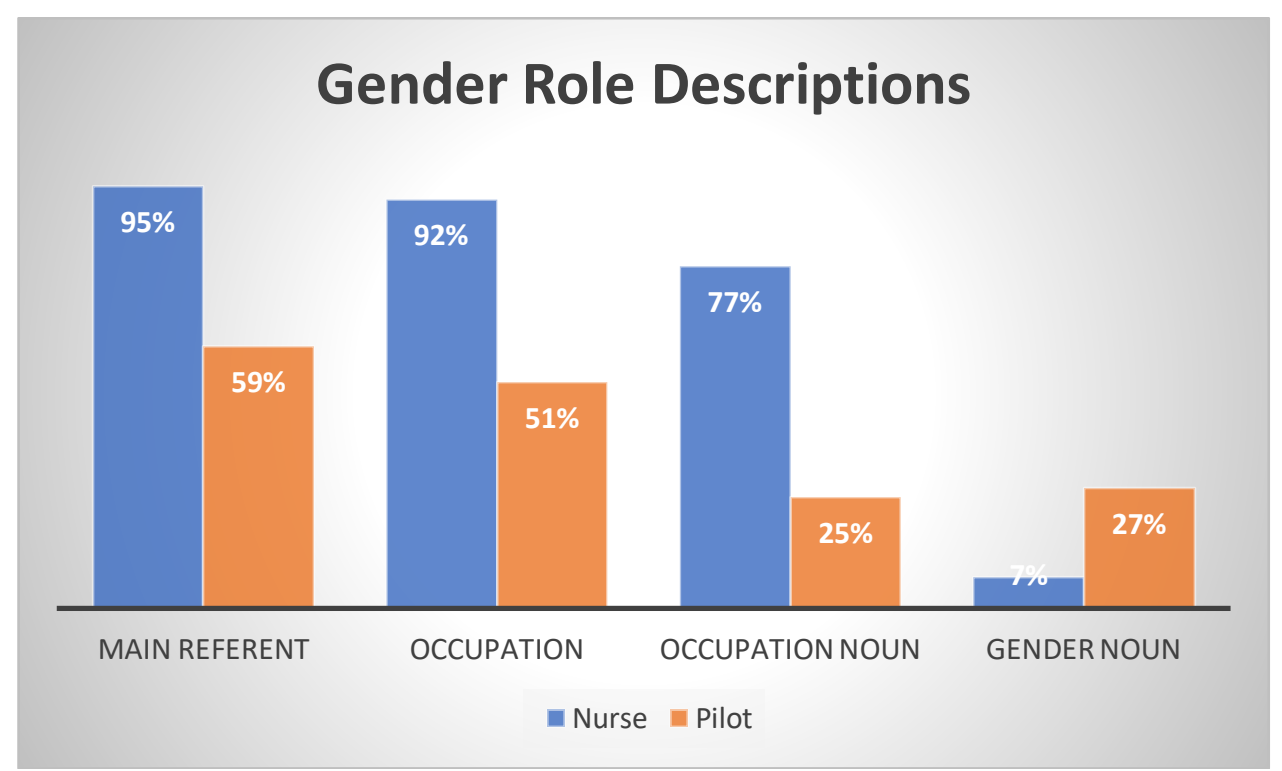

Figure 5-Comparison of descriptions for Pilot and Nurse

Both the man and woman were the dominant feature in each picture. It was expected that they would both be the main referent in the descriptions. This expectation was met for the descriptions of the man, with 95 per cent discussing him as the main referent. For example, survey \#65 stated

The man appears to be a nurse going about his daily routine. This appears to be the case as he is holding a clipboard and pushing an IV line.

However, in 41 per cent of the descriptions about the woman, she was secondary or not mentioned. For example, "advertising a holiday, a getaway, fresh start, break" (Survey \#69). Moreover, 92 per cent of descriptions referenced the man's occupation, with 77 per cent of descriptions using his occupation as the subject noun to describe him. For instance, survey \#69 stated "Doctor viewing a patient and will put in an IV line". In contrast, 51 per cent of descriptions referenced the woman's occupation, with 25 per cent of descriptions using her occupation as the subject noun to describe her.

The use of a person's occupation as a subject noun is a type of linguistic labelling referred to as a noun label. Beukeboom and Burgers (2019) posit that using noun labels activates stereotype content associated with that label category and that noun labels have a binary quality to them. Thus, the prevalent use of occupation as a noun label for the man activates stereotype content associating men with workplace roles. Social role theory highlights that gender roles place men in the workplace, the use of noun labels here illustrates how gender stereotypes can be communicated and reinforced through variations in language. On the other hand, the prevalent use of female subject nouns in the same context only activates stereotype associations of women. Female subject nouns are like the explicit marking of sex, outlined in Part Two, whereby their use draws attention to the woman as being a woman and not as being a professional. For example, survey \#65 stated "the woman is advertising for pilots".

Further analysis of these descriptions illustrated more asymmetrical trends. 49 per cent of descriptions that did not discuss the woman's occupation, for the man this was 8 per cent. 
To gain insight, the descriptions of the woman were assessed for common themes, five were identified. Each description was linked to one theme, the hierarchy being occupation, advertisement, recruitment, travel and other. The pie chart, Figure 7, below illustrates the breakdown of descriptions associated with these themes.

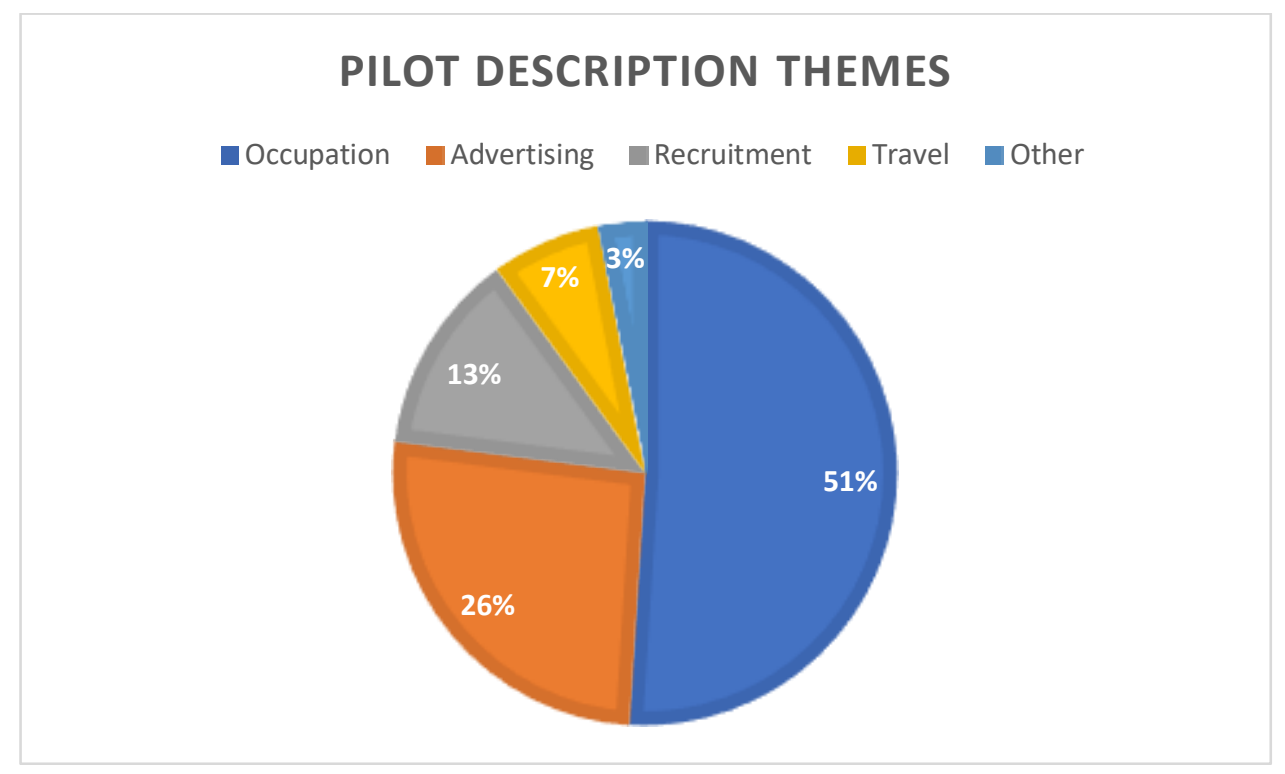

Figure 6 - Main themes of descriptions of picture with Pilot

Almost two fifths of descriptions centred on the themes of advertising and recruitment. Most of these descriptions did not mention the woman. For example, survey \#14 and \#55 stated:

This to me looks like an airline advertisement with a plane travelling the globe

Virgin Airline was my 1st thoughts. Richard Branson. "Train people well enough they can leave, treat them well so they won't want to leave."

One explanation for this could be that women, in these instances, become secondary to what they are promoting. This could be because society is used to seeing women utilised in this way, that is, as an actor model for advertising and not as a pilot. This again highlights the existence of gender stereotyping in terms of gender roles.

Taking all these findings into consideration, 68 per cent of the descriptions of the pilot assigned her a lower status or marked her as different in some way. Collectively, these findings imply that gender roles are reasonably active in the NS. These findings also highlight how stereotype content can be influenced by societal expectations. Research (Hentschel et al, 2019) suggests that where gender distribution is skewed in the workplace thus can fuel the persistence of traditional gender stereotypes. Considering the NS has a gender distribution of over 93 per cent men, this could provide an explanation for influence of traditional gender roles on gender stereotypes in the findings above. The existence of stereotypes can also be demonstrated by evaluating labels; therefore, the next section will examine this link. 
Labels

To clarify the use of labels identified by Beukeboom and Burgers (2019) as an inherent part of transmitting and reinforcing stereotypes, the survey explored the use of category and derogatory terms and the values ascribed to them. Labels, whether heard or read, can activate the stereotype content associated with this label, thus providing a way of accessing stereotypical beliefs. Participants were provided with the labels 'slut', 'creep', 'asshole', 'ballbreaker', 'emotional' and 'arrogant', and were asked to:

- Associate the label gender as being male, female, or both

- Associate the label valence as being negative, positive, or neutral

- Provide a description of the characteristics they would associate with this label

Simple statistical analysis was first applied to the data in terms of these associations. The findings are illustrated in Table 2.

Table 2 - Labels

\begin{tabular}{|c|c|c|c|c|c|c|}
\hline & $\begin{array}{c}\text { Male } \\
\text { Association }\end{array}$ & $\begin{array}{c}\text { Female } \\
\text { Association }\end{array}$ & $\begin{array}{c}\text { Both } \\
\text { Association }\end{array}$ & $\begin{array}{c}\text { Negative } \\
\text { Association }\end{array}$ & $\begin{array}{c}\text { Neutral } \\
\text { Association }\end{array}$ & $\begin{array}{c}\text { Positive } \\
\text { Association }\end{array}$ \\
\hline Creep & $70 \%$ & - & $30 \%$ & $90 \%$ & $10 \%$ & - \\
\hline Slut & - & $71 \%$ & $29 \%$ & $81 \%$ & $15 \%$ & $4 \%$ \\
\hline Arrogant & $26 \%$ & $1 \%$ & $73 \%$ & $87 \%$ & $12 \%$ & $1 \%$ \\
\hline Emotional & - & $43 \%$ & $57 \%$ & $16 \%$ & $69 \%$ & $15 \%$ \\
\hline Asshole & $42 \%$ & - & $58 \%$ & $91 \%$ & $8 \%$ & $1 \%$ \\
\hline Ballbreaker & $17 \%$ & $17 \%$ & $64 \%$ & $65 \%$ & $29 \%$ & $6 \%$ \\
\hline
\end{tabular}

The findings did not entirely concur with the concept that labels transmit stereotypes. For example, the labels 'arrogant', 'asshole', 'ballbreaker' and 'emotional' did not return a majority association to one gender. Research (Smith et al, 2018) previously identifies 'arrogant' and 'asshole' as male labels, and 'emotional' as a female label. One explanation for this could be that in the NS these labels are equally associated with both genders. However, based on 19 years of personal experience in the NS, this explanation did not seem entirely sufficient.

To gain greater insight into this anomaly, further examination of the data was conducted. This involved disaggregating the data by sex of participant and cross tabulating in terms of how valence was being attributed to each label and to each gender association within that label. This provided an alternative view to the data and revealed an alternative explanation for the reduced gender associations of these labels. Table 3 provides a summary of the findings. They are presented as a correlation between the valence attributions and gender category 
attributions given by the male participants. These figures are represented as a percentage of the gender category attribution for that label. ${ }^{3}$

Table 3 - Male participant valence associations

\begin{tabular}{|c|c|c|}
\hline Creep & Highest Negative Associations & $\begin{array}{c}\text { Highest Positive/Neutral } \\
\text { Associations }\end{array}$ \\
\hline Slut & $97 \%$ Both & $15 \%$ Male \\
\hline Arrogant & $90 \%$ Female & $46 \%$ Both \\
\hline Emotional & $91 \%$ Both $^{4}$ & $18 \%$ Male \\
\hline Asshole & $22 \%$ Female & $91 \%$ Both \\
\hline Ballbreaker & $98 \%$ Both & $14 \%$ Male \\
\hline
\end{tabular}

What stands out in the table is the association of positive/neutral valence with men and negative valence with women. This points towards a male pattern of positive self-presentation and negative 'other' presentations, which was discussed in Part Two. This asymmetry in valence associations to gender categories can have distinct implications that impact how men and women are viewed. Considering that labels are inherently linked with stereotypes, and behaviours and traits associated with these stereotypes are inferred to be dispositional, by associating a higher level of negative valence to women suggests that women are responsible for the negative connotations the label implies. Conversely, the high neutral/positive valence associations with men suggests men are responsible for the positive connotations the label implies.

Further information observed in the data analysis that supports this finding was the inclusion, by men, of female comparisons in the descriptions of 'negative and male' behaviours, illustrated in the comments below.

III-mannered and selfish. The male equivalent of "bitch" (Survey \#72)

Would be a bitch if a woman. Loves screwing co-workers/subordinates over, universally hated (Survey \#102)

Research (Smith et al, 2018) has illustrated an asymmetry in the assigning of negative attributes more significantly to women. This finding appears to concur with this research. The trend of highlighting female negative behaviours can elicit negative feelings towards. These

\footnotetext{
${ }^{3}$ For example, emotional had 36 'female' attributions and 8 'negative and female' attributions, therefore the percentage calculation was $8 / 36=22 \%$

${ }^{4} 100 \%$ for females, but only 1 female association, therefore it was felt that this data was not sufficient for inclusion.
} 
negative feelings can in turn be used to justify prejudicial or discriminatory actions against them, as was illustrated in the example of the Magdalene Laundries.

C onsidering all findings thus far, the answer, in part, to the first two research questions is that these findings indicate gender stereotypes exist in the NS and they appear to be notably prevalent. Focus will now move to examining the data analysis for language variations when discussing stereotype expected and unexpected behaviours. These findings will be presented and discussed in the next section.

\section{Language Variations}

According to research (Beukeboom \& Burgers, 2019), communications about stereotypically expected and unexpected behaviours should vary. Therefore, analysing descriptions can provide insight into stereotypical beliefs. If language variations are linked to stereotypical beliefs it would be expected that descriptions of counter stereotypical behaviours, provided by participants, will infer external attribution for these behaviours. This could include the use of concrete language, individuating information, or explanations for the behaviour. Conversely, it would be expected that descriptions of stereotypical behaviours, provided by participants, will infer dispositional attribution for these behaviours. This could include the use of abstract language, providing stereotype confirming information, or discussing personality characteristics, and qualities and characteristics of the person's social category. The survey tested these theories in several ways.

To test the theory that the level of abstraction used in describing behaviours is linked to stereotypical beliefs, the survey contained a series of pictures with multiple choice answers, these can be viewed in Appendix 2. These answers varied in their level of abstraction, as per the LCM. Participants were asked to rate each statement by how likely they were to use it to describe the behaviour portrayed in the picture. According to LEB, stereotypical behaviours should return a majority ADJ selection and counter stereotypical behaviours a majority DAV selection. The picture of the boys fighting and the woman littering returned responses consistent with this expectation. However, the picture of the woman helping the old lady across the road returned a majority DAV selection, this was not expected. There are several possible explanations for this inconsistency. First, the sentences provided for the survey may have inadvertently steered participants towards a particular response, this may also have been possible for the consistent results. Second, helping may not be stereotypically associated with women by personnel of the NS. Third, due to the 98 per cent positive association with this picture, if women were considered to be the 'out-group' in the NS, then LIB theory dictates that favourable behaviours of out-group members are discussed using more concrete terms, that is, DAVs. The third explanation has similarities with the key finding in the labels section, which pointed towards a pattern of male positive self-presentation and negative 'other' presentation. However, further research around inter group bias would be required to establish more than a tentative link between these findings.

Considering this section contained closed questions, it was not possible to measure the variations in people's everyday language. Therefore, data analysis was carried out on participant's descriptions of male and female behaviours to ascertain the nuances in their language use. Based on the high usage of abstract descriptions for the picture of the women gossiping, see Figure 8 , this would suggest that this behaviour is part of the stereotype content 
NS personnel have of women. Also, many of these descriptions inferred that it is a woman's disposition to gossip. Some of the descriptions given by the men are illustrated below:

Typical female behaviour (Survey \#54)

Women at their best (Survey \#76)

A bunch of bitches with nothing better to do than gossip (Survey \#100)

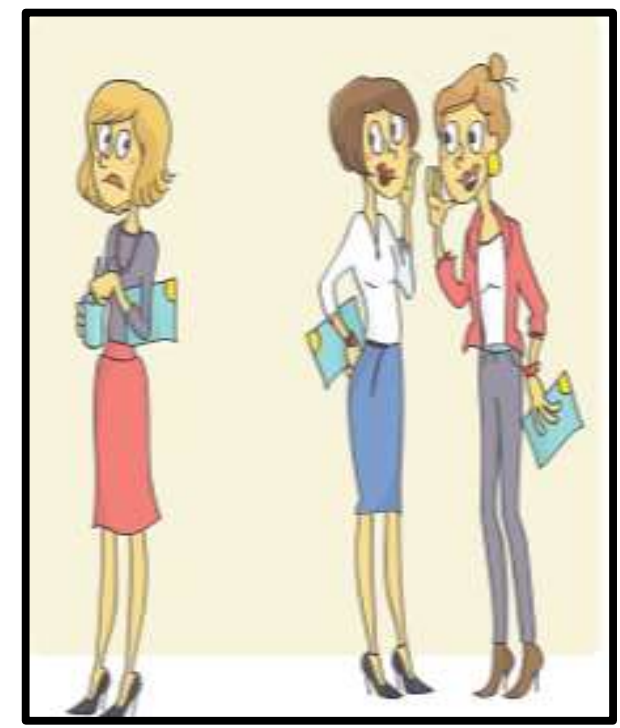

Figure 7-Survey Picture of Stereotypically Expected Female Behaviour

Further explanatory information can be derived from the content of these descriptions. The most context given in any description was the number of women and where they were standing. Also, the most individuating information given was information that confirms the stereotype or gives a mental image of the stereotype. For example, survey \#46 stated:

Two office colleagues gossiping about the other colleague in the picture, about her recent actions at the office Christmas party. This is apparent by the way the women are speaking from the sides of their mouths with their hands covering and the worried look on the other's face.

The predominant use of abstract descriptions, dispositional inferences, and stereotype confirming information are entirely consistent with Beukeboom and Burgers' (2019) SCSC framework. It could thereby be suggested that this type language use when describing women serves to maintain and reinforce gender stereotypes in the NS.

In direct contrast to the above finding, the descriptions of the man crying, seen in Figure 9, indicate that crying not part of the stereotype content NS personnel have of men. Further analysis of the descriptions is outlined below. Some of the theories that underpin the findings are abstraction and SEB. 


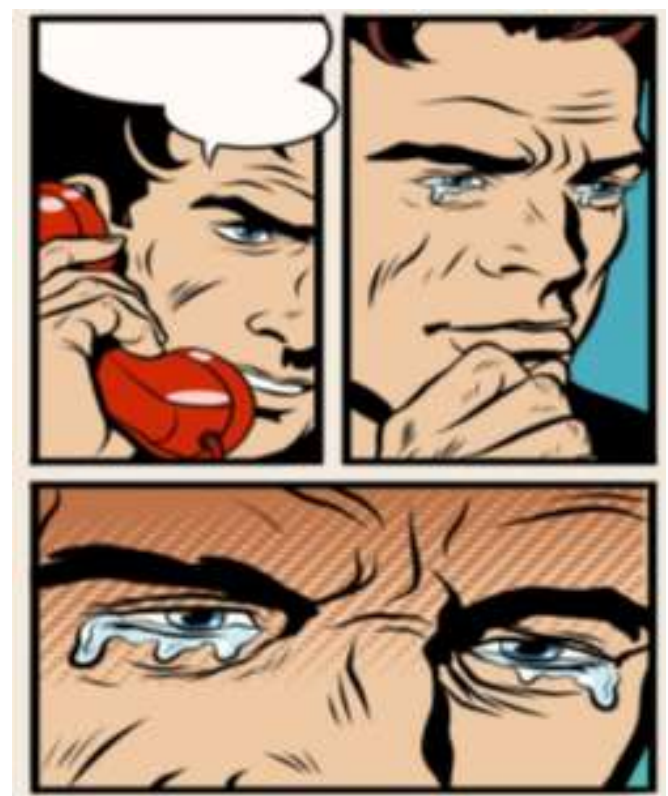

Figure 8 - Survey Picture of Stereotypically Unexpected Male Behaviour

87 per cent of the descriptions displayed very low levels of abstraction, with 94 per cent of all descriptions providing an explanation for the man's behaviour. For example:

He has just received a call to inform him of the passing of his sick mother. This is apparent because he is on the phone and when he comes off it and is visibly upset by the conversation that took place (Survey \#44)

Figure 10 provides a breakdown of the explanations provided, most relating to bad news or a death.

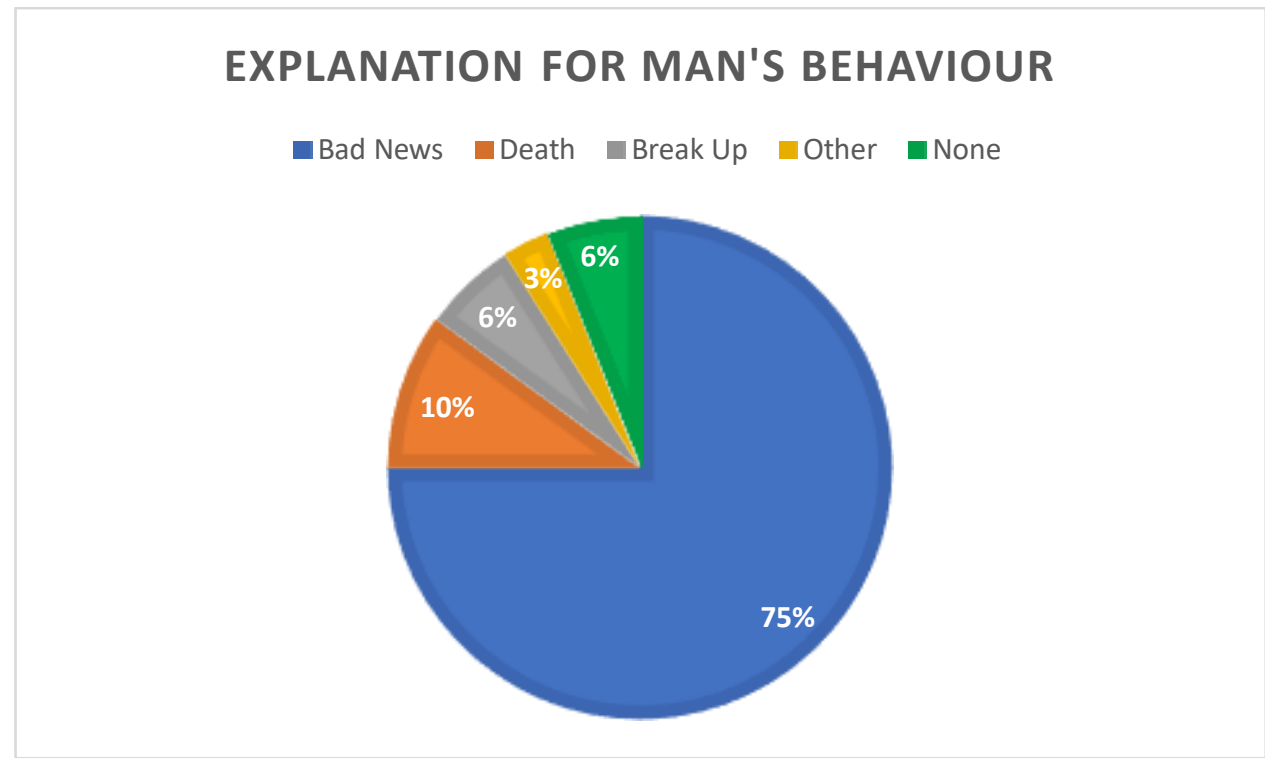

Figure 9 - Explanations for Man's Behaviour

This finding could be viewed as an example of SEB because when behaviours are counter stereotypical, people tend to provide an explanation thereby providing external attribution for 
the behaviour. Furthermore, 63 per cent of all descriptions provide context by mentioning the phone, and 55 per cent of all descriptions directly attribute the phone call as the reason for the man's behaviour. For example:

A man has received a phone call. The news he has received has made him upset and he is crying (Survey \#75)

In summary, the findings presented in this section indicate that gender stereotypes and gender biased language exist in the NS are moderately prevalent, thus answering the first and second research questions.

Some of the key findings from this section are as follows:

- Both stereotype content and linguistic biases displayed asymmetries that advantaged men more than women.

- Stereotype beliefs appear to be more than moderately influenced by traditional gender roles. This suggests that men are being ascribed a higher status than women resulting in a reinforcing the male dominated hierarchy in the NS

- An asymmetry exists in how men and women are communicated about. This asymmetry creates a positive male self-presentation and draws attention to the negative traits of women.

Burgers and Beukeboom highlight that prejudice is most likely to occur "in cases in which affective evaluations of members of a social category are negative" (2020, p.17). Based on this evaluation and the findings of the survey, there is an expectation that women in the NS will have experienced prejudice. However, to confirm this and thus answer the third research question, the next section will examine the data from the critical incident reports.

\section{Critical Incident Report Analysis}

To discern the real-life consequences stereotypes and gender bias language have on women in the NS, five serving NS women were asked to provide an account of incidents where they felt they had been wronged because of their gender. How these incidents bring to life women's experiences will be explored, reflecting the findings in the sections above. To ensure anonymity of participants, certain details such as timings, places, people etc. have been changed. However, in all cases, the context of the situation has remained the same.

Thematic analysis of the reports identified the following key themes, in relation to gender stereotypes and gender biased language:

- Motherhood

- Inappropriate behaviours of a sexual nature

- Scapegoating

Three of the five reports contained the theme of motherhood. Accounts emphasised how the label of 'mother' came with societal expectations and organisational perceptions, that created situations in which they felt prejudiced, if not discriminated, against. Two of these reports highlighted decisions made by their superiors based on stereotype expectancies surrounding motherhood, with one person commenting: 
it was the $1^{\text {st }}$ time someone within the NS blatantly made an assumption that I would not want a career once I became a mother

One participant recalled her superior stating he was not considering her for certain appointments "out of concern for the possibility of me getting pregnant and wanting to ensure the least amount of disruption to occur". The other participant recalled after raising an expression of interest for a "coveted" appointment being met with a flabbergasted expression and the comment "but who is going to mind your children". On the surface, both these incidents may appear innocuous and only show superiors expressing concern for these females' welfare. However, assumptions were made about the women based on stereotypical beliefs, that appear to be strongly influenced by traditional gender roles. The consequence is different standards of treatment are being applied to the two women than would be to men in the same situation. In both these cases, limiting boundaries are being placed on both women that could, and will, impact their range of experience for career development and advancement in the future. As Beukeboom and Burgers (2019) point out, discrimination occurs when an individual or a group is "treated, described, and/or judged based on generic social category associations rather than individuating information" $(2019$, p.5). Therefore, although the superiors may have made these statements and decisions out of concern, they may not have understood the consequences their reliance on their stereotypical beliefs would have on both these women, not only from a career advancement viewpoint but also from a personal impact viewpoint. Tate and Page (2018) point out that the premise of implicit bias is that the person is unaware of their bias and therefore social injustice is maintained as a result.

Remaining on the theme of motherhood, a second sub-theme emerged from the data analysis of the reports, that is, the sharing of stereotype confirming information. Referring again to traditional gender roles, there is high societal expectations of women to become mothers. Information that confirms this stereotype expectancy is regularly shared. One participant highlighted the unauthorised, "gossip-like" sharing of information pertaining to her newly discovered pregnancy throughout the NS - "I had to deal with the entire Navy knowing I was pregnant at an early stage". The consequence of which created increased levels of anxiety for her which could have impacted on her health or the health of her unborn child. However, another report highlighted that prevalence for sharing or discussing information in the NS that confirms the stereotype of women as mothers does not cease after pregnancy. She stated:

I am routinely asked about my family (at work). I feel I am asked about this because having children is what defines me to my peers and superiors. I am very conscious that my male colleagues are not asked about their families not their childcare arrangements - it is assumed that their partner manages this.

These examples highlight how gender stereotype beliefs can create an asymmetry in the treatment of women in the NS. The consistent sharing of information relating to women and motherhood serves to focus attention on NS females being mothers, this being the most important and defining information about them rather than being service personnel. Like the other examples provided in this theme, they appear innocuous in nature, but they perpetuate stereotypes in a manner that ascribes a lower status to women. Accordingly, these stereotypes can have negative consequences for their career progression and advancement, consequences 
that do not exist for their male counterparts. The sentiment of this asymmetry was echoed in all reports, with all women commenting that this would not have happened to a man in the NS.

Turning now to the second theme identified in the data analysis of the reports; inappropriate behaviours of a sexual nature. One of the most serious findings in the data analysis concerned unwanted and inappropriate comments and advances of a sexual nature on females in the organisation. Two of the five reports discussed this narrative, one of a much more serious nature than the other. In the more serious case, the woman reported the event to her superior. However, she believes how the case was handled was more reprehensible than the harassment, sexual and otherwise, she was subjected to, stating she was "appalled at what happened to me, but more appalled at how it was handled". Collins and Clément note that

beliefs about a particular social group, affect the nature and quality of interactions with members of that group, whether it is to censure what is said or to qualify what is heard. (2012, p.376)

Based on the details provided in this report, Collins and Clément's statement rings true. It was explained to the participant that what happened to her onboard "was a rare occurrence and only happened to me because I was a female and we draw more attention than males" that "it would be in everyone's best interest for this incident to go away as quickly as possible" and "I was told to keep this to myself". These statements and the use of language in them led the participant to "feel guilty....it was my fault that this had happened to me....... because I was female, I was made to feel that I had brought this type of behaviour on myself". The participant felt her superior "only wanted the problem to go away and not have to deal with it", showing no empathy towards her or any concern for her welfare.

In the other case provided, the female felt,

Comments were extremely inappropriate towards me. I usually ignored it as I didn't want to be the one to tell him to leave me alone. We worked so closely together and he was one of the lads, I really felt trapped in an awkward position.......... It was a constant battle of trying to humour him, without being seen as a bitch........ When you are working so closely with someone, you never want to be the one to complain. I always felt like it would damage me more than him...... Where do I draw the line between wanting to be treated equally and not wanting to be seen as easily offended

Both these examples raise questions about how inappropriate sexual behaviours towards women are perceived by both men and women in the NS. The second example appears to suggest an element of normalcy about this type of behaviour, with the respondent resigning herself to accepting this treatment. Both examples also suggest that the current complaints system is not fit for purpose. In the first example, a complaint was made but it was felt that the issue was brushed under the carpet, so to speak, and the respondent felt an element of victim blaming. In the second example, the female participant felt it would be more damaging for her to report this inappropriate behaviour than to put up with these repeated incidents. This view was echoed in other reports. In several reports there was a shared perspective that submitting a complaint would result in them being scapegoated. 
One respondent proposed that:

going against organisational culture would have been too detrimental to my personal standing within the organisation

One of the most pervasive features of any type of discrimination is the denial it even exists. The findings presented in this section allude to a bias in the treatment of men and women in the organisation. They also suggest an element of organisational acceptance and normalisation of practices that disadvantage women in the NS, by both men and women. Interestingly, one report commented that

some of the strongest, most amazing, capable women in the DF are so normalised to sexism towards them they do not see it

This sentiment was illustrated in several reports, when some women made excuses or rationalisations to explain the inappropriate behaviours or actions towards them. For example, one woman noted

The comment did make me more aware that I would have to be prepared for similar negative comments

Therefore, rather than seeing this behaviour as prejudiced and not to be tolerated, this woman rationalised it and just prepared herself for more of the same.

Oxford maintains that,

the processes and mechanisms surrounding derogatory language, gendered socialisations and social stigma, may seem and feel as though they are normal; however they are critical processes that reproduce a cultural hegemony that continues to shape and constrain female participation within organisations (2019, p.1026)

The findings reviewed here seem to align with this statement. They suggest that the answer to third research question is that gender stereotypes and gender bias language limit women in the NS, in terms of career development and advancement. They also appear to normalise and marginalise biased and prejudiced behaviours towards women to such an extent that these behaviours are rationalised by the women themselves. The next and concluding section of this chapter will summarise all the analysis and findings in this chapter into several key points.

This section presented and discussed the findings from the data analysis of the surveys and critical incident reports. The following key points highlight what this study revealed.

- Regarding gender stereotypes, findings from both the survey and critical incident reports suggest that they do exist in the NS and that they take a reasonably active role. The findings also indicated that the content of these stereotypes is not neutral, ascribing a higher status to men. Traditional gender stereotypes appear to be most prominent, with men predominantly being viewed in a professional capacity and women in the role of mother. 
- In terms of gender biased language, findings in the survey analysis suggested the existence of linguistic biases in the NS. These findings were underpinned by several of the linguistic bias theories outlined in Chapter Two. An asymmetry exists in how men and women are communicated about. This asymmetry creates a positive male selfpresentation and draws attention to the negative traits of women.

- Both stereotypes and linguistic biases have had negative effects on women. Critical incident reports provided accounts which illustrated some of the limiting effects stereotypes and linguistic biases had in terms of career development and progression.

Overall, the findings appear to point towards a negative depiction of women. Research (Glick \& Fiske, 2001) suggests that depicting women in this way will elicit negative feelings towards them thereby providing justification for traditional gender roles, maintaining a male dominated hierarchy, and men's consideration of women as sexual.

\section{PART FOUR. Conclusion}

We cannot change what we are not aware of, and once we are aware, we cannot help but change.

(Sheryl Sandberg, 2013)

\section{Gender Stereotypes}

Data analysis pertaining to both the survey and critical incident reports revealed that gender stereotypes exist in the NS and they appear to be relatively active. These stereotypes appear to be predominantly influenced by traditional gender roles. They also appeared to be biased in men's favour. The process of stereotype activation and association operating at an unconscious level is a significant problem. It is one which enables and normalises subtle forms of gender discrimination to occur. These gender stereotypes and consequent subtle discriminations can have a pervasive way of reinforcing the existing male dominated hierarchy, thus potentially hindering women's aspirations, retentions, and promotions.

\section{Gender Biased Language}

Findings from the survey analysis established the existence of gender biased language. Although survey participants only provided a representative sample of 11 per cent of the NS, since language is the embodiment of culture, moderate correlations can be made to the wider NS. The analysis demonstrated further asymmetries in how gender biased language was being applied to, and by, men and women. The findings uncovered a trend of men depicting themselves in a much more positive light than women. They distanced themselves from being associated with negative traits and behaviours in several ways. These included the use of concrete descriptions, explanations and situational behaviour descriptions which inferred external attribution for their negative behaviour; they also were more inclined to attribute positive valence to themselves. This was demonstrated in several of the findings. Consequently, there was a trend of highlighting women's negative traits behaviours. This was done by using abstract language in conjunction with female noun subjects which inferred dispositional attribution for their negative behaviour. This depiction of women in a negative light, according to research, can be a form of sexism that can be used to justify traditional gender roles, maintaining a male dominated hierarchy, and men's consideration of women as sexual. 
Further Consequences for Women in the NS

Critical incidents reports highlighted a perception, by the women, of scapegoating if they reported incidents they believed prejudicial, discriminatory, or inappropriate. The findings alluded to an element of organisational acceptance and normalisation of these practices. Consequently, women appeared to become socialised to these practices, demonstrating acceptance and providing rationalisations for them.

\section{Recommendations}

Several recommendations were forthcoming from the data analysis and findings that would have an impact on addressing the problems gender stereotypes and linguistic bias are creating for gender equality in the NS. These will be discussed under the following headings.

- Training and education

- HR policy review

- Implementation of a separate complaints system

Raising awareness about stereotypes, biases, and the negative, unrealised consequences they can have is fundamental to tackling this issue. To illustrate this point, the following analogy is provided. When a person purchases a new car, they suddenly see that make and model of car everywhere. This is not because there has been a sudden increase in sales of that car, it is because their awareness of this type of car has become part of their conscious psyche resulting in them noticing it more. Raising awareness about stereotypes and bias in a constructive and controlled manner works on the same premise as the car. Once people become more aware of their existence, they will notice them more and can therefore do something to stop them. Therefore, it is recommended that an education and training programme be implemented. This should be mandatory for all personnel, with attendance required on a two to three yearly basis, like the manual handling course.

There are barriers to genuine equality that are embedded in organisational structures, cultures, and policies. These must be recognised and overturned if equality, not just gender equality, is to exist in the organisation. One policy lacking in transparency or policy, is the selection of personnel for courses, appointments, overseas etc. Therefore, it is recommended that a review of the selection process for all appointments, courses etc. should ensue with a view to creating a policy that ensures transparency, fairness, and equality of opportunity for all personnel. It should also ensure accountability of the decision makers and an ongoing review process of all selections to ensure 'coveted' appointments or courses are being allocated in a fair and transparent manner.

It is recommended that complaints of incidents of a sexual nature be dealt with using a system that is separate from the current complaints system. The current system does not appear to be fit for purpose for these complaints, either for the complainant or the accused. It is believed that these cases require specialist input and should be dealt with by people with the required expertise and qualifications. The findings from the critical incident reports of victim blaming, scapegoating and trying to resolve issues as quickly as possible imply that the current system is biased and flawed, which could result in women being too afraid to report serious, and possibly criminal, incidents of a sexual nature. 


\section{Further Research}

There are many areas of potential research arising from this study. However, the two areas it is believed will provide the best insight and have the greatest impact on gender inequalities in the NS and wider PDF are:

- How women's career aspirations can be limited by language variations in their annual appraisals

- The dynamics and consequences of intergroup bias and "othering" of women in the organisation

One of the most common and reprehensible features of prejudice and discrimination is the denial it even exists. Prejudice and discrimination do not require intention for them to ensue. Much of the gender discrimination that occurs in society "is enacted unintentionally with no intention to harm" (Ogunnaike et al, 2010). Tennant (2017) argues that most discussions about gender discrimination often result in predictable comments about the trivial nature of the issue. There needs to be a realisation that it is this type of attitude that contributes to perpetuating power and authority at the expense of the marginalised.

To conclude, there is a requirement that the inequalities and barriers that exist for women in the NS are acknowledged and accepted as being real. If this point is not conceded, then things will never change.

Please note that the views expressed in this article are those of the author alone and should not be taken to represent the views of the Irish Defence Forces, the Command and Staff School or any other group or organisation.

\section{BIBLIOGRAPHY}

About the Magdalene Laundries (n.d.) Retrieved July 20, 2021 from Justice for Magdalene's Research website: https://www.jfmresearch.com/home/preserving-magdalenehistory/about-the-magdalene-laundries/

Akinlolu M., \& Haupt T.C. (2020). Investigating a Male-Dominated Space: Female Students' Perceptions of Gendered Cultures in Construction Workplaces. In: C. Aigbavboa and W. Thwala (Eds.) The Construction Industry in the Fourth Industrial Revolution. Springer, Cham: CIBD.

Allison, P. (2000). Research from the ground up: Post-expedition adjustment. Ambleside: Brathay.

Allport, G. (1954). The nature of prejudice. Reading, MA: Addison-Wesley.

Antonesa, M., Fallon, H., Ryan, A.B., Ryan, A., Walsh, T., \& Borys, L. (2006). Researching and Writing Your Thesis: A Guide for Postgraduate Students. MACE, Maynooth.

Archer, E. M. (2012). The Power of Gendered Stereotypes in the US Marine Corps. Armed Forces and Society, 39(2), 359-391. 
Aronoff, M., \& Rees-Miller, J. (2017). The handbook of linguistics, second edition (2nd ed.) Wiley-Blackwell.

Ashwell, L. (2016). Gendered slurs. Social Theory and Practice, 42(2), 228.

Assilaméhou-Kunz, Y., Postmes, T., \& Testé, B. (2020). A normative perspective on the linguistic intergroup bias: How intragroup approval of ingroup members who use the linguistic intergroup bias perpetuates explicit intergroup bias. European Journal of Social Psychology, 50(1), 81-96. doi:10.1002/ejsp.2616

Augoustinos, M., \& Every, D. (2007). The language of "race" and prejudice: A discourse of denial, reason, and liberal-practical politics. Journal of Language and Social Psychology, 26, 123-141.

Bahns, A. J. (2017). Threat as justification of prejudice. Group Processes \& Intergroup Relations, 20(1), 52-74.

Banton, M. (2011). A Theory of Social Categories. Sociology, 45(2), 187-201. doi.org/10.1177/0038038510394013

de Beauvoir, S. (1993). The Second sex. Translated and edited by H. M. Parshly, London: David Campbell Publishers Ltd.

Berryman, D. R. (2019). Ontology, Epistemology, Methodology, and Methods: Information for Librarian Researchers. Medical Reference Services Quarterly, 38(3), 271-279. doi: 10.1080/02763869.2019.1623614

Beukeboom, C. J. (2012). Mechanisms of linguistic bias: How words reflect and maintain stereotypic expectancies. In J. Laszlo, J. Forgas, \& O. Vincze (Eds.), Social cognition and communication. New York: Psychology Press.

Beukeboom, C. J., \& Burgers, C. (2017). Linguistic Bias. Oxford Research Encyclopaedia of Communication, 1-23.

Beukeboom, C. J., \& Burgers, C. (2019). How Stereotypes Are Shared Through Language: A Review and Introduction of the Social Categories and Stereotypes Communication (SCSC) Framework. Review of Communication Research, 7, 1-37.

Beukeboom, C. J., Finkenauer, C., \& Wigboldus, D. H. J. (2010). The negation bias: When negations signal stereotypic expectancies. Journal of Personality and Social Psychology, 99(6), 978-992. doi:10.1037/a0020861

Brannon, L. (2017). Gender: Psychological Perspectives. Seventh Edition, New York: Routledge.

Burgers, C., \& Beukeboom, C.J. (2016). Stereotype Transmission and Maintenance Through Interpersonal Communication: The Irony Bias. Communication Research, 43(3), 414-444.

Burgers, C., \& Beukeboom, C. (2020). How language contributes to stereotype formation: Combined effects of label types and negation use in behavior descriptions. Journal of Language and Social Psychology. 10.1177/0261927X20933320

Burrell, G., \& Morgan, G. (2016). Sociological Paradigms and Organisational Analysis. Abingdon: Routledge. 
Cameron, D. (1992). Researching language: Issues of power and method. London;New York;: Routledge.

Carnaghi, A., \& Maass, A. (2007). In-group and out-group perspectives in the use of derogatory group labels: Gay versus fag. Journal of Language and Social Psychology, 26, 142156.

Coates, J. (1993). Women, men, and language: A sociolinguistic account of gender differences in language (2nd ed.). London; New York: Longman.

Collins, K. A., \& Clément, R. (2012). Language and prejudice: Direct and moderated effects. Journal of Language and Social Psychology, 31(4), 376-396.

Cortina, L. M. (2008). Unseen Injustice: Incivility as Modern Discrimination in Organizations. The Academy of Management Review, 33(1), 55-75.

Cralley, E. L., \& Ruscher, J. B. (2005). Lady, girl, female, or woman: Sexism and cognitive busyness predict use of gender-biased nouns. Journal of Language and Social Psychology, 24(3), 300-314.

Creswell, J. W., \& Plano Clark, V. L. (2007). Designing and conducting mixed methods research. Thousand Oaks, Calif: SAGE Publications.

Criado-Perez, C. (2019). Invisible women: Exposing data bias in a world designed for men. London: Chatto \& Windus.

Cronley, C., \& Kim, Y. k. (2017). Intentions to turnover: Testing the moderated effects of organisational culture, as mediated by job satisfaction, within the Salvation Army. Leadership \& Development Journal, 38(2), 194-209.

Crotty, M. (1998). The Foundations of Social Research. London: Sage.

Department of Defence. (2015). White Paper on Defence August 2015. Retrieved from: https://www.gov.ie/en/publication/1b0dc6-white-paper-on-defence/

Department of Defence. (2019). White Paper on Defence: Update 2019. Retrieved from: https://www.gov.ie/en/publication/a519cf-white-paper-on-defence-update-2019/

Department of Foreign Affairs. (2019). Women, Peace and Security. Ireland's third National Action Plan for the implantation of UNSCR 1325 and related resolutions, 2019-2024. Retrieved from:https://www.dfa.ie/media/dfa/ourrolepolicies/womenpeaceandsecurity/Third-NationalAction-Plan.pdf

Department of Justice. (2017). National Strategy for Women and Girls 2017-2020. Retrieved from:http://www.justice.ie/en/JELR/Pages/National Strategy for Women and Girls 2017$\underline{2020}$

Denzin, N. K., \& Lincoln, Y. S. (2018). The sage handbook of qualitative research (Fifth ed.). Los Angeles: Sage.

Dipboye, R. L., Wooten, K., \& Halverson, S. K. (2004). Behavioural and situational interview. In J.C. Thomas (Ed.), Comprehensive Handbook of Psychological Assessment, (297-316). Hoboken, NJ: John Wiley \& Sons Inc. 
van Dijk, T. A. (1987). Communicating racism: Ethnic prejudice in thought and talk. Sage Publications, Inc.

Douglas, K. M., \& Sutton, R. M. (2003). Effects of communication goals and expectancies on language abstraction. Journal of Personality and Social Psychology, 84, 682-696.

https://doi.org/10.1037/0022-3514.84.4.682

Eagly, A. H., \& Wood, W. (2016). Social Role Theory of Sex Differences. In N. Naples, R. C. Hoogland, M. Wickramasinghe, \& W. C. A. Wong (Eds.), The Wiley Blackwell Encyclopedia of Gender and Sexuality Studies.

Eckert, P., \& McConnell-Ginet, P. (2003). Language and Gender. Cambridge, U.K.: Cambridge University Press.

Equal Measures 2030. (2019). Harnessing the Power of Data for Gender Equality: Introducing the 2019 EM2030 SDG Gender Index. Retrieved from www.data.em2030.org/2019-globalreport

Fiske, S. T., Cuddy, A. J. C., Glick, P., \& Xu, J. (2002). A model of (often mixed) stereotype content: Competence and warmth respectively follow from perceived status and competition. Journal of Personality and Social Psychology,82, 878-902.

Ford, L. (2020, March 5). Nine out of 10 people found to be biased against women. The Guardian. https://www.theguardian.com/global-development/2020/mar/05/nine-out-of-10people-found-to-be-biased-against-women

Fox, G. (2019, February 24). Meet the neuroscientist shattering the myth of the gendered brain. The Guardian. https://www.theguardian.com/science/2019/feb/24/meet-theneuroscientist-shattering-the-myth-of-the-gendered-brain-gina-rippon

García-Ael, C., Cuadrado, I., \& Molero, F. (2018). The Effects of Occupational Status and SexTyped Jobs on the Evaluation of Men and Women. Frontiers in psychology, 9, 1170.

Gordon, J. K., Andersen, K., Perez, G., \& Finnegan, E. (2019). How Old Do You Think I Am? Speech-Language Predictors of Perceived Age and Communicative Competence. Journal of Speech, Language, and Hearing Research, 62, 2455-2472.

Gough, B., McFadden, M., \& McDonald, M. (2013). Critical social psychology: An introduction (2nd ed.). Houndmills, Basingstoke: Palgrave Macmillan.

Griffin, R. (2019, July 29). Institutional patriarchy alive and well in Ireland. The Irish Times.https://www.irishtimes.com/opinion/institutional-patriarchy-alive-and-well-in-ireland1.3969872 on $08 / 01 / 2020$ )

Guba, E. G., \& Lincoln, Y. S. (1994). 'Competing paradigms in qualitative research'. In N. K. Denzin \& Y S. Lincoln (Eds.), Handbook of qualitative research. Thousand Oaks, CA: Sage, 105116. 
Haslam, S., Oakes, P., McGarty, C., Turner, J., Reynolds, K., \& Eggins, R. (2011). Stereotyping and social influence: The mediation of stereotype applicability and sharedness by the views of in-group and out-group members. British Journal of Social Psychology, 35, 369 - 397.

Haynes, K. (2012). 'Reflexivity in qualitative research'. In C. Cassell \& B. Lee (Eds), Challenges and Controversies in Management Research. New York: Routledge.

Hedger, J. A. (2013). Meaning and racial slurs: Derogatory epithets and the semantics/pragmatics interface. Language \& Communication, 33, 205-213.

Hegarty, P., \& Pratto, F. (2001). The effects of social category norms and stereotypes on explanations for intergroup differences. Journal of Personality and Social Psychology, 80(5), 723-735. doi:10.1037/0022-3514.80.5.723

Hellinger, M., \& Bußmann, H. (2003). Gender across languages: The linguistic representation of women and men. volume 3. Philadelphia: John Benjamins Publishing Company.

Hellinger, M., Bußmann, H., \& Hellenger, M. (2001). Gender across languages: The linguistic representation of women and men. volume 1. Philadelphia: John Benjamins Publishing Company.

Hellinger, M., \& Bußmann, H. (2000). Gender across languages: The linguistic representation of women and men. volume 2. Philadelphia: John Benjamins Publishing Company.

Hentschel, T., Heilman, M. E., \& Peus, C. V. (2019). The multiple dimensions of gender stereotypes: A current look at men's and women's characterizations of others and themselves. Frontiers in Psychology, 10(11), 1-19. doi:10.3389/fpsyg.2019.00011

Hinton, P. (2017). Implicit stereotypes and the predictive brain: Cognition and culture in "biased" person perception. Palgrave Communications, 3(1), 1-9.

doi:10.1057/palcomms.2017.86

Hogg, M., \& Vaughan, G. (2005). Social Psychology (4th edition). London: Prentice-Hall.

Hogg, M., \& Smith, J. (2007). Attitudes in social context: A social identity perspective. European Review of Social Psychology, 18(1), 89-131.

Holmes, J. (1992). An introduction to sociolinguistics. London;New York;: Longman.

Horvath, L. K., Merkel, E. F., Maass, A., \& Sczesny, S. (2016). Does gender-fair language pay off? the social perception of professions from a cross-linguistic perspective. Frontiers in Psychology, 6 doi:10.3389/fpsyg.2015.02018

Hoy, W. K., \& Adams, C. M. (2016). Quantitative research in education: A primer (Second ed.). Thousand Oaks, California: SAGE Publictions, Inc.

Johnson, R., Onwuegbuzie, A., \& Turner, L. (2007). Toward a Definition of Mixed Methods Research. Journal of Mixed Methods Research, 1, 112-133. doi:10.1177/1558689806298224. 
Jones, K., Arena, D., Nittrouer, C., Alonso, N., \& Lindsey, A. (2017). Subtle discrimination in the workplace: A vicious cycle. Industrial and Organizational Psychology-Perspectives on Science and Practice, 10(1), 51-76.

Kristoffersson, E., Andersson, J., Bengs, C., \& Hamberg, K. (2016). Experiences of the gender climate in clinical training-a focus group study among Swedish medical students. BMC medical education, 16(1), 283.

Lakoff, R. T. (1975). Language and woman's place. New York: Harper \& Row.

Lan, T., \& Jingxia, L. (2019). On the gender discrimination in english. Advances in Language and Literary Studies, 10(3), 155-159. doi:10.7575/aiac.alls.v.10n.3p.155

LeClair, J. (2018). Does Gender-Fair Language Equal Gender-Fair Culture? Available at https://medium.com/@declairjoshua/does-gender-fair-language-equal-gender-fair-culture8dbc5ab36c30 (Accessed on: 11 Oct 2019)

Lilienfeld, S. O. (2017). Microaggressions: Strong Claims, Inadequate Evidence. Perspectives on Psychological Science, 12(1), 138-169. https://doi.org/10.1177/1745691616659391

Lukianoff, G., \& Haidt, J. (2015). The coddling of the American mind. The Atlantic. Retrieved from: http://www.theatlantic.com/magazine/archive/2015/09/the-coddling-of-the-american$\underline{\operatorname{mind} / 399356 /}$

Maass, A. (1999). Linguistic intergroup bias: Stereotype perpetuation through language. In M. P. Zanna (Ed.), Advances in experimental social psychology, 31, 79-121. San Diego, CA: Academic Press.

Maass, A., \& Acuri, L. (1996). Language and stereotyping. In C. N. Macrae, C. Stangor, \& M. Hewstone (Eds.), Stereotypes and stereotyping. 193-226. New York, NY: Guilford Press.

Maass, A., Salvi, D., Arcuri, L., \& Semin, G. R. (1989). Language use in intergroup contexts: The linguistic intergroup bias. Journal of Personality and Social Psychology, 57, 981-993.

doi:10.1037/0022-3514.57.6.981

MacArthur, H. J., Cundiff, J. L., \& Mehl, M. R. (2019). Estimating the prevalence of genderbiased language in undergraduates' everyday speech. Sex Roles, 1-13. doi:10.1007/s11199019-01033-z

Martin, P., \& Barnard, A. (2013). The experience of women in male-dominated occupations: a constructivist grounded theory inquiry. SA J. ind. Psychol, 39, 2-12.

McDonald, H. (2013, February 5) Ireland finally admits state collusion in Magdalene Laundry System. The Guardian. https://www.theguardian.com/world/2013/feb/05/irelandmagdalene-laundry-system-apology

McLeod, S. A. (2018). Attitudes and behavior. Simply Psychology. Available at: https://www.simplypsychology.org/attitudes.html (accessed 09 Jan 2020).

McLeod, S. A. (2019). Social identity theory. Simply Psychology. Available at: https://www.simplypsychology.org/social-identity-theory.htm (accessed 10 Nov 2019). 
Menegatti, M., \& Rubini, M. (2017). Gender Bias and Sexism in Language. Oxford Research Encyclopaedia of Communication. Retrieved 12 Feb. 2020, from https://oxfordre.com/communication/view/10.1093/acrefore/9780190228613.001.0001/acre fore-9780190228613-e-470.

Moncrieffe, J., \& Eyben, R. (2013). The power of labelling: How people are categorized and why it matters doi:10.4324/9781849773225

Gender, Diversity and Equality (n.d.) Retrieved Feb 13, 2020 from Irish Defence Forces website: https://www.military.ie/en/public-information/defence-forces-families/genderdiversity-equality/

Morris, M. (1996). By Force of Arms: Rape, War, and Military Culture. Duke Law Journal, 651781.

$\mathrm{Ng}$, S. H. (2007). Language-based discrimination: Blatant and subtle forms. Journal of Language and Social Psychology, 26, 106-122.

Ogunnaike, O., Dunham, Y., \& Banaji, M. R. (2010). The language of implicit preferences. Journal of Experimental Social Psychology, 46, 999-1003.

Otterbacher, J. (2015). Linguistic Bias in Collaboratively Produced Biographies: Crowdsourcing Social Stereotypes? ICWSM.

Oxford, S. (2019). 'You look like a machito!': a decolonial analysis of the social in/exclusion of female participants in a Columbian sport for development and peace organisation. Sport in Society, 22(6), 1025-1042.

Patton, M. Q. (2002). Qualitative research and evaluation methods (3rd ed.). Thousand Oaks, Calif: Sage Publications.

Redfern, J. R. (2007). Gender Fair Language. Retrieved from:

https://www.cyut.edu.tw/ /hli/rmtw/A10.pdf

Robinson, W. P., \& Giles, H. (2001). The new handbook of language and social psychology. Chichester, England;New York;: J. Wiley.

Ruscher, J. B., \& Tipler, C. N. (2018). Linguistic intergroup bias about the 2016 U.S. presidential candidates as a function of political ideology. Analyses of Social Issues and Public Policy, 18(1), 61-80.

Sagan, C. (1995). Demon-haunted world: Science as a candle in the dark. New York, NY:

Random House.

Saunders, M., Lewis, P., \& Thornhill, A. (2019). Research methods for business students (8.th ed.). Harlow: Pearson Education Limited.

Schommer-Aikins, M. (2002). An evolving theoretical framework as an epistemological belief system. In K. B. Hofer, \& R. P. Pintrick (Eds.), Personal Epistemology: The psychology of beliefs about knowledge and knowing, 103-115. London: Routledge. 
Seih, Y., Beier, S., \& Pennebaker, J. W. (2017). Development and examination of the linguistic category model in a computerized text analysis method. Journal of Language and Social Psychology, 36(3), 343-355. doi:10.1177/0261927X16657855.

Semin, G. R. (2012). The linguistic category model. In P. A. M. Van Lange, A. W. Kruglanski, \& E. T. Higgins (Eds.), Handbook of theories of social psychology (p. 309-326). Sage Publications Ltd. https://doi.org/10.4135/9781446249215.n16

Semin, G. R., \& Fiedler, K. (1988). The cognitive functions of linguistic categories in describing persons: Social cognition and language. Journal of Personality and Social Psychology, 54, 558568. https://doi.org/10.1037/0022-3514.54.4.558

Sen, G. (2019). Gender equality and women's empowerment: Feminist mobilization for the SDGs. Global Policy, 10(S1), 28-38. doi:10.1111/1758-5899.12593.

Sekaquaptewa, D., Espinoza, P., Thompson, M., Vargas, P., \& von Hippel, W. (2003).

Stereotypic explanatory bias: Implicit stereotyping as a predictor of discrimination. Journal of Experimental Social Psychology, 39, 75- 82. doi:10.1016/S0022-1031(02)00512-7

Shariatmadari, D. (2019). Don't believe a word: The surprising truth about language. Orion Publishing, London, UK.

Sheehan, A., Berkery, E., \& Lichrou, M. (2017). Changing role of women in the Irish society: an overview of the female consumer. The Irish Journal of Management, 36, 162 - 171.

Sheridan, F. (2007). Gender, language and the workplace: An exploratory study. Women in Management Review, 22(4), 319-336.

Sibley, C., \& Barlow, F. (2016). An Introduction to the Psychology of Prejudice. In: Sibley, C. and Barlow, F. eds (2016) The Cambridge Handbook of the Psychology of Prejudice.

Cambridge: Cambridge University Press. 3-20.

Smith, D. G., Rosenstein, J. E., Nikolov, M. C., \& Chaney, D. A. (2019). The power of language: Gender, status, and agency in performance evaluations. Sex Roles, 80(3-4), 159-171.

Smith, D. G., Rosenstein, J. E., \& Nikolov, M. C. (2018, May 25). The different words we use to describe male and female leaders. Harvard Business Review. https://hbr.org/2018/05/thedifferent-words-we-use-to-describe-male-and-female-leaders

Speer, S. A. (2005). Gender talk: Feminism, discourse and conversation analysis. London: Routledge Ltd. doi:10.4324/9780203321447

Spender, D. (1980). Man Made Language. London: Routledge \& Kegan Paul.

Stenbacka, C. (2001). Qualitative research requires quality concepts of its own. Management Decision, 39(7), 551-555.

Stout, J. G., \& Dasgupta, N. (2011). When he doesn't mean you: Gender-exclusive language as ostracism. Personality and Social Psychology Bulletin, 37, 757-769. 
Sunstein, C. R. (2015). Picking the right words to ban from campus. Bloomberg View. Retrieved from http://www.bloombergview.com/articles/2015-06-23/picking-the-rightwords-to-ban-from-campus

Sutton, R. M. (2010). The creative power of language in social cognition and intergroup relations. In H. Giles, S. A. Reid, \& J. Harwood (Eds.), The dynamics of intergroup communication, 105-115. New York, NY: Peter Lang.

Swim, J. (2007). Stereotypes, prejudice, and discrimination. Retrieved from Penn State University edu Web site: https://edge.psu.edu/workshops/mc/stereotypes/page 02.shtml

Taber, N. (2011). 'You better not get pregnant while you're here': tensions between masculinities and femininities in military communities of practice. International Journal of Lifelong Education, 30(3), 331-348. doi: 10.1080/02601370.2011.570871

Tate, S., \& Page, D. (2018). Whiteliness and institutional racism: hiding behind (un)conscious bias, Ethics and Education, 13:1, 141-155 doi:10.1080/17449642.2018.1428718

Taylor, D. M., \& Usborne, E. (2007). Is the social psychology of language a genuine field of study? Journal of Language and Social Psychology, 26, 204-211.

Tajfel, H., Turner, J. C., Austin, W. G., \& Worchel, S. (1979). An integrative theory of intergroup conflict. Organizational identity: A reader, 56-65.

Tennant, E. (2017). Ol' Man River - how gendered language shapes the way we see the world. Available at: https://theconversation.com/ol-man-river-how-gendered-language-shapes-theway-we-see-the-world-87700 (Accessed: 11 Oct 2019)

Thompson, M. S., Judd, C. M., \& Park, B. (2000). The consequences of communicating social stereotypes. Journal of Experimental Social Psychology, 36(6), 567-599.

doi:10.1006/jesp.1999.141902

Tsoukas, H., \& Chia, R. (2011). Introduction: Why philosophy matters to organization theory. Research in the Sociology of Organizations, 32(1), 1-21.

United Nations Development Programme. (2020). Tackling Social Norms; A game changer for gender inequalities. Retrieved from

http://hdr.undp.org/sites/default/files/hd perspectives gsni.pdf

Wang, R. (2016). In: Farzad sharifian (ed.), the routledge handbook of language and cultures. london: Routledge, 2015.

Wellington, J., Bathmaker, A.-M., Hunt, C., McCulloch, G., \& Sikes, P. (2005). Succeeding with Your Doctorate. London: SAGE Publications Ltd.

Wescott, K. (2011, May 9). Why is the word 'slut' so powerful? BBC News Magazine. https://www.bbc.com/news/magazine-13333013 
Wetherell, M., \& Potter, J. (1992). Mapping the language of racism: Discourse and the legitimation of exploitation. New York: Columbia University Press.

Wigboldus, D. H. J., Semin, G. R., \& Spears, R. (2000). How do we communicate stereotypes? Linguistic bases and inferential consequences. Journal of Personality and Social Psychology, 78, 5-18.

Wood, W., \& Eagly, A. H. (2011). Social role theory. In P. A. M. van Lange, A. W. Kruglanski, and E. T. Higgins (Eds.), Handbook of theories in social psychology, Thousand Oaks, CA: Sage Publications.

Wright, S. C., \& Bougie, É. (2007). Intergroup contact and minority-language education: Reducing language-based discrimination and its negative impact. Journal of Language and Social Psychology, 26, 157-181.

Zosuls, K. M., Miller, C. F., Ruble, D. N., Martin, C. L., \& Fabes, R. A. (2011). Gender development research in sex roles: Historical trends and future directions. Sex Roles, 64(11), 826-842. doi:10.1007/s11199-010-9902-3 